\title{
Family Process and Youth Internalizing Problems: A Triadic Model of Etiology and Intervention
}

\section{Citation}

Scheider, Jessica L., and John R. Weisz. 2017. Family Process and Youth Internalizing Problems: A Triadic Model of Etiology and Intervention. Development and Psychopathology 29: 273-301.

\section{Permanent link}

http://nrs.harvard.edu/urn-3:HUL.InstRepos:41542958

\section{Terms of Use}

This article was downloaded from Harvard University's DASH repository, WARNING: This file should NOT have been available for downloading from Harvard University's DASH repository.

\section{Share Your Story}

The Harvard community has made this article openly available. Please share how this access benefits you. Submit a story. 


\title{
Family process and youth internalizing problems: A triadic model of etiology and intervention
}

\author{
JESSICA L. SCHLEIDER AND JOHN R. WEISZ \\ Harvard University
}

\begin{abstract}
Despite major advances in the development of interventions for youth anxiety and depression, approximately $30 \%$ of youths with anxiety do not respond to cognitive behavioral treatment, and youth depression treatments yield modest symptom decreases overall. Identifying networks of modifiable risk and maintenance factors that contribute to both youth anxiety and depression (i.e., internalizing problems) may enhance and broaden treatment benefits by informing the development of mechanism-targeted interventions. A particularly powerful network is the rich array of family processes linked to internalizing problems (e.g., parenting styles, parental mental health problems, and sibling relationships). Here, we propose a new theoretical model, the triadic model of family process, to organize theory and evidence around modifiable, transdiagnostic family factors that may contribute to youth internalizing problems. We describe the model's implications for intervention, and we propose strategies for testing the model in future research. The model provides a framework for studying associations among family processes, their relation to youth internalizing problems, and family-based strategies for strengthening prevention and treatment.
\end{abstract}

Depression and anxiety disorders in children and adolescents (youths) are impairing, distressing, and prevalent (e.g., Campo et al., 2004; Garber \& Weersing, 2010; Lewinsohn, Hops, Roberts, Seeley, \& Andrews, 1993; Weersing, Rozenman, Maher-Bridge, \& Campo, 2012). Anxiety disorders affect up to $20 \%$ of youths prior to the age of 18 (Beesdo, Knappe, \& Pine, 2009; Bell-Dolan, Last, \& Strauss, 1990), and lifetime prevalence estimates approach $25 \%$ beginning in adolescence (Kessler et al., 2012; Lewinsohn et al., 1993). Of note, rates of comorbidity between anxiety and depression are consistently high: in community samples, $25 \%-50 \%$ of depressed youths also meet criteria for an anxiety disorder, and $10 \%-15 \%$ of anxious youths meet for concurrent depression (Angold, Costello, \& Erkanli, 1999; Cummings, Caporino, \& Kendall, 2014). Early work proposed that anxiety and depression overlap to such a degree that a common form of dysfunction, "neurotic disorder," might encompass them both (Eysenck, 1967; Eysenck \& Eysenck, 1975; Rutter, et al., 1969). More recent theoretical models have identified features distinctive to anxiety and depression, attributing their overlap to shared etiologic influences (Barlow, Allen, \& Choate, 2004; Cole, Truglio, \& Peeke, 1997; McLaughlin \& Nolen-Hoeksema, 2011). Anxiety in childhood has been identified as a predictor and risk factor for the development of subsequent depression (Cole et al., 1997; Garber \& Weersing, 2010; Schleider, Krause, \& Gillham, 2014), and the reverse pattern has also been observed (Moffitt et al., 2007).

Address correspondence and reprint requests to: Jessica L. Schleider, Psychology Department, Harvard University, 33 Kirkland Street, Cambridge, MA 02138; E-mail: jschleider@fas.harvard.edu.
These patterns have led to a growing body of research on transdiagnostic approaches to the etiology and treatment of youth anxiety and depression, or the "internalizing" youth problem cluster (Ehrenreich-May \& Bilek, 2012; Ehrenreich-May \& Chu, 2013; Ivanova et al., 2007; Trosper, Buzzella, Bennett, \& Ehrenreich, 2009; Wadsworth, Hudziak, Heath, \& Achenbach, 2001; Weisz, Santucci, Bearman, \& Jensen-Doss, 2016; Weisz et al., 2012). Separately, using latent modeling techniques to parse the meta-structure of psychiatric diagnoses, Krueger, Chentsove-Dutton, Markon, Goldberg, and Ormel (2003) and Krueger and Markon $(2011,2014)$ found that both anxiety and depressive disorders reflect a shared, core internalizing dimension: a propensity to experience distress inwardly. As such, any risk factors shaping the core internalizing dimension are hypothesized to affect both kinds of disorders. Drawing upon transdiagnostic principles and a possible latent internalizing domain may help identify networks of risk factors, some potentially modifiable, that cut across the development of both anxiety and depression, and may thus inform the search for mechanisms to be addressed in interventions for youth internalizing problems.

As one example of the relevant evidence, many components of family process have been shown to predict anxiety and depression in youths, including parental psychopathology, poor family functioning, and certain kinds of parentyouth interactions. However, in the vast majority of youth psychotherapy, families play a limited role (Breinholst, Esbjorn, Reinholdt-Dunne, \& Stoller, 2012). In prominent cognitive behavioral therapy protocols for youth anxiety (e.g., Coping Cat; Kendall \& Hedtke, 2006) and depression (e.g., PASCET; Weisz et al., 2005; and CWD-A; Clarke \& DeBar, 
2010), parental participation is limited to a few psychoeducation-based sessions, and there are no explicit suggestions for including siblings in the treatment process. Although these treatments are effective in many cases, $25 \%$ to $30 \%$ of youths do not respond to traditional cognitive behavioral therapy (CBT) for anxiety (Kendall, Furr, \& Podell, 2010), and overall, youth depression treatments yield modest symptom decreases (meta-analytic $d=0.34$; Weisz, McCarty, \& Valeri, 2006). The rich evidence base documenting the impact of family processes on youth anxiety and depression suggests that a synthesis of knowledge in this domain may point the way toward more effective intervention. For instance, it may suggest strategies for augmenting existing treatments with family-focused modules, reveal promising familial targets for prevention efforts, and in some cases spur the creation of new treatments.

However, there is not yet an evidence-informed framework for exploring how various family processes shape the onset and maintenance of youth internalizing problems, broadly construed, nor how they might inform intervention design. There are at least two reasons for this gap. First, components of family process (e.g., parenting styles and parental psychopathology) are generally examined as individual risk and maintenance factors for youth internalizing problems, so their combined effects on these problems remain unclear. Second, family process is typically explored in relation to youth anxiety or depression rather than both kinds of problems. However, many of the same family factors have been shown to influence risk for youth anxiety and depression (Drake \& Ginsburg, 2012; Sander \& McCarty, 2005), consistent with Krueger and Markon (2011) and Krueger et al.'s $(2003,2014)$ proposed internalizing dimension in the metastructure of psychopathology, which encompasses both kinds of disorders. Further, family factors can jointly influence risk for internalizing problems both incrementally (Appleyard, Egeland, van Dulmen, \& Sroufe, 2005; Sameroff, 2000) and jointly or interactively (Schleider, Patel, Krumholz, Chorpita, \& Weisz, 2015; Weems \& Stickle, 2005), although the structure and patterns that characterize these effects have not been comprehensively explored.

In line with this evidence, we describe a new theoretical model, the triadic model of family process, for exploring relations between components of family process and youth anxiety and depression. Building on previous work focused on the structure and nature of covariation of anxiety and depressive symptoms (Clark \& Watson, 1991; Krueger 2003, 2014; Krueger \& Markon, 2011), we focus on antecedents, risk factors, and maintenance factors that might affect internalizing problems in general. Specifically, we describe a framework that may facilitate investigations of how different components of family process relate to each other and to youth internalizing problems. Such research may suggest networks of familial risk factors that can help account for the development and maintenance of internalizing dysfunction and that may represent promising targets for youth interventions.

\section{Components of Family Process: Parent-Level, Dyad-Level, and Family-Level Factors}

Within the triadic model of family process, illustrated in Figure 1, various family processes are hypothesized to influence social, affective, and cognitive processes in youths. In turn, changes in these youth processes may either potentiate or protect against the development and maintenance of internalizing disorders. To organize and incorporate the many variables that shape family processes, this model suggests three different "levels" of family-related factors, defined as follows:

- Parent-level factors are defined as aspects of family process localized within or between parents or caregivers (e.g., parental mental health; single vs. dual-parent family structure; and interparental interaction)

- Dyad-level factors are defined as aspects of family process localized within parent-child or sibling relationships (e.g., parenting styles; parental feedback to youths; parental modeling; and sibling relationship quality)

- Family-level factors are defined as aspects of family process involving the family's functioning as a collective unit (e.g., family stability; family functioning; and differential parent treatment of siblings)

Factors on these three levels are thought to affect each other, youth processes, and youth internalizing problems in four primary ways. First, factors within the same level can influence and interact with each other (e.g., interparental interaction characterized by conflict might affect the presence or course of parent psychopathology, and vice versa). Further, family-related factors on all three levels may influence factors on all other levels. For instance, a parent-level factor such as interparental conflict may affect family-level factors, such as family functioning, and dyad-level factors, such as parenting styles. In turn, these family- and dyad-level factors may have reciprocal effects on interparental conflict. Second, factors on all three levels may shape the development and maintenance of youth processes spanning cognitive, social, and affective domains (factors from different levels may additively or interactively affect the same youth process). Third, youth social, affective, and cognitive processes may influence the development and maintenance of internalizing problems. Fourth, youth internalizing problems may affect aspects of family process at the parent, family, and dyad levels (Bell, 1968, 1979; Kim et al., 2009). Thus, this model addresses the likely reciprocal, continual relations between family process and youth problems.

This paper is organized according to the model's structure, as well as these four principles. We review parent-, dyad-, and family-level factors that have been found to predict and maintain youth anxiety and depression. For each level, we will describe how specified factors might lead to and sustain youth internalizing problems through their impact on specific youth processes. After reviewing these individual factors and pro- 


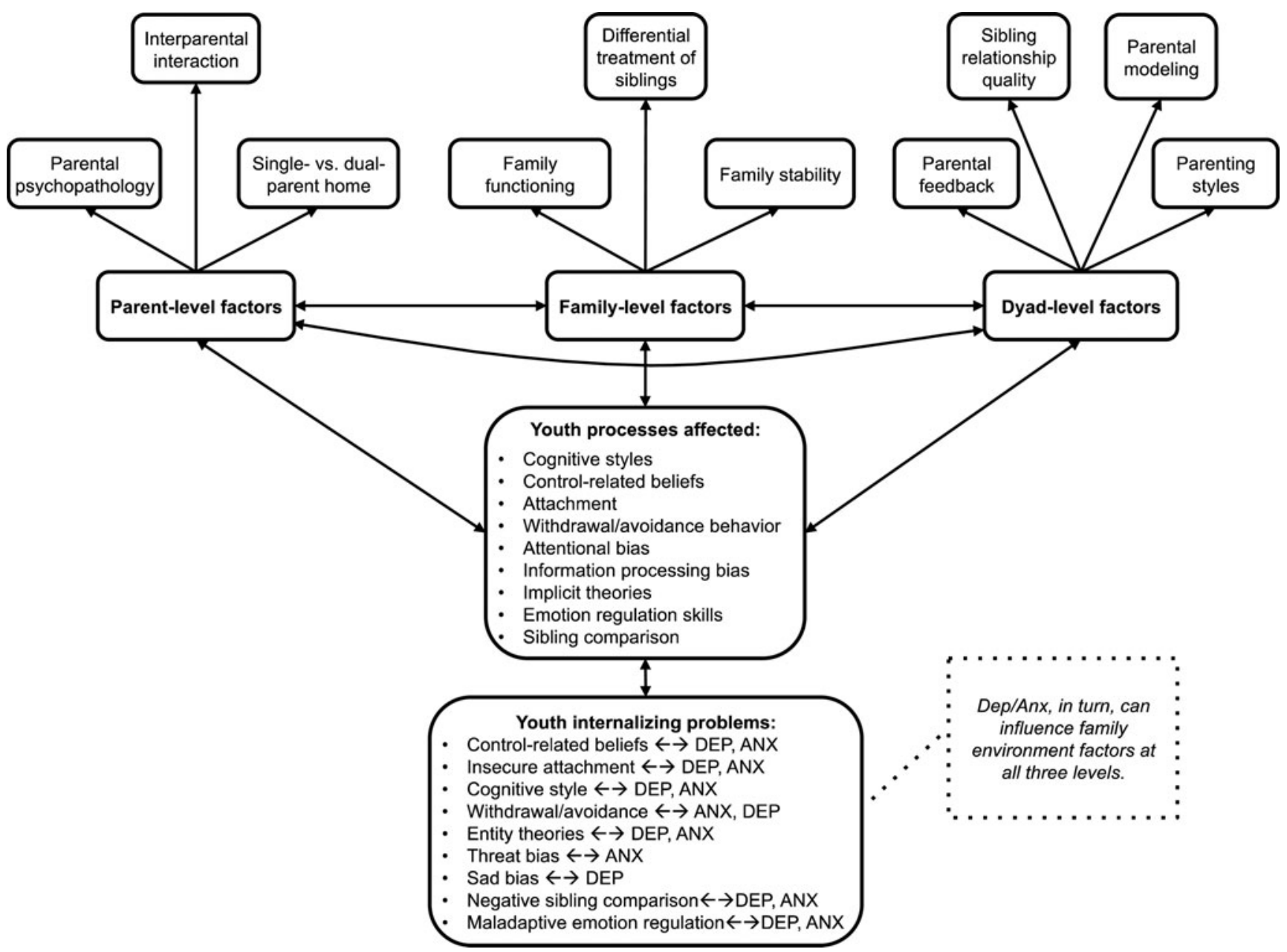

Figure 1. Triadic model of family process.

cesses, we describe ways of conceptualizing and exploring how factors at multiple levels may jointly contribute to the onset and maintenance of youth internalizing problems. Finally, we describe related implications for the treatment and prevention of youth internalizing problems and outline strategies for testing the triadic model through longitudinal, experimental, and intervention effectiveness research.

In addition, for factors at all levels, we discuss the model in relation to two child factors (age and gender) that are often linked to the etiology of internalizing disorders. Prior to adolescence, boys and girls tend to experience depression at comparable rates (Anderson, Williams, McGee, \& Silva, 1987; Hankin et al., 1998; Kashani, Cantwell, Shekim, \& Reid, 1982). However, beginning around age 13, depression in girls increases rapidly; girls remain twice as likely as boys to experience depression throughout middle to late adolescence and adulthood (Ge, Lorenz, Conger, Elder, \& Simons, 1994; Hankin et al., 1998). An important gender difference is also observed in rates of anxiety: by age 6 , girls are already twice as likely as boys to have experienced an anxiety disorder (Lewinsohn, Gotlib, Lewinsohn, Seeley, \& Allen, 1998). Separately, regarding age of onset, anxiety disorders tend to emerge during middle childhood and early adolescence (with the exception of social anxiety, which tends to emerge later; Eisen, Brien, Bowers, \& Strudler, 2001; Lewinsohn et al., 1998), whereas depression most often makes its first appearance in adolescence (Angold \& Rutter, 1992; Hankin et al., 1998). Given these patterns, we include discussions of how parent-, dyad-, and family-level factors may affect children differently as a function of age or gender. We hope this will facilitate and inform developmentally tailored applications of the triadic model in longitudinal, experimental, and effectiveness research.

Finally, before detailing the model, three caveats should be noted. First, the aspects of family and youth processes discussed in this paper are not intended to be exhaustive. Rather, we focus on specific parent-, dyad-, and family-level factors, as well as youth processes, that are well represented in the developmental psychopathology literature and in ways that suggest links to internalizing dysfunction. We suggest that this framework can be applied to a wide variety of family variables not identified here, as well as youth processes not mentioned.

Second, the role of socioeconomic factors, race, and ethnicity in this model merits discussion. Each of these factors 
may influence both family processes and risk for youth internalizing problems, and the relations and mechanisms described here should be considered in the context of a family's socioeconomic circumstances and background. However, we have chosen not to address socioeconomic variables or race/ethnicity in this model for two reasons. (a) Although these variables can affect family process, they do not themselves describe how family members relate to one another or function as a unit. Thus, socioeconomic factors and race/ ethnicity may be more aptly understood as possible external influences on family process. (b) An important reason for our focus on family process is that family factors are, with a few exceptions, modifiable via psychological interventions. That is, factors like parental psychopathology and parenting styles may be plausible intervention targets. Socioeconomic variables are unlikely to be realistic targets for such interventions. Thus, this model focuses on relational aspects of family process that may potentially be targeted in psychosocial treatments for youths.

Third, the present model does not incorporate biological and genetic factors related to youth internalizing problems. Although a number of such vulnerabilities are evident in youth anxiety and depression, these factors operate within a social context that can have powerful effects. Moreover, relatively little is known currently about which specific biological factors are amenable to intervention, or what strategies may be effective in modifying those factors. Thus, for intervention-optimization purposes, it is useful to explore social factors common to the development of different youth internalizing problems, and to organize a synthesis of the relevant evidence.

\section{Parent-level factors}

We will focus on two parent-level factors: parent psychopathology and interparental interaction, including parental separation and relationship satisfaction. Below, we briefly review evidence supporting each factor's relation to youth internalizing problems. We then discuss candidate youth processes that might mediate links between parent-level factors and youth internalizing problems. Finally, we consider whether child age and gender might shape the effects of parent-level factors on youth internalizing problems.

Parent psychopathology. Numerous prospective, longitudinal studies have identified parents' psychiatric symptoms as risk and maintenance factors for internalizing problems in youth (Anderson \& Hammen, 1993; Burstein \& Ginsburg, 2010; Goodman, 2007; Hammen, 2009; Weissman, Warner, Wickramaratne, Moreau, \& Olfson, 1997; Weissman et al., 2006). Beidel and Turner (1997), for instance, found that the frequency of psychiatric disorders in offspring of anxious or depressed parents was considerably higher (36\%-45\%) than evident in children of nonpsychiatric controls $(10 \%)$. A 10-year longitudinal investigation revealed that offspring of depressed parents were eight times more likely to experi- ence depression and five times more likely to develop an anxiety condition than the offspring of parents without psychiatric problems (Wickramaratne \& Weissman, 1998). Ten years later (during adulthood), the cumulative rate of anxiety or depression was three times that of control participants (Weissman et al., 2006). Evidence suggests that parental anxiety is more specifically related to anxiety problems in youth, whereas offspring of depressed parents show increased anxiety and depression (Avenevoli \& Merikangas, 2006; Biedel \& Turner, 1997).

Single-versus dual-parent family structure. Compared with youths raised by two parents in the same household, youths raised by a single parent tend to have more internalizing problems and suffer more social and academic impairment (Martins \& Gaffan 2000; Olson, Ceballo, \& Park, 2002). These differences tend to persist after accounting for socioeconomic proxies, such as considerably higher poverty rates in singleparent versus dual-parent families (Brooks-Gunn \& Duncan, 1997; Dawson, 1991; Dodge, Pettit, \& Bates, 1994). Further, while some research suggests that associations between youth problems and family structure are contingent upon ethnicity, other studies have found that minority status does not consistently moderate this relation (Wight, Aneshenel, Botticello, \& Sepúlveda, 2005).

Interparental interaction: Relationship dissatisfaction. In general, research suggests that youths' perspectives on interparental interaction, specifically whether parents express relationship dissatisfaction and engage in frequent fighting, predicts their subsequent functioning more reliably than family structure (e.g., living in a single-parent home; for a review, see Cummings, 1994). Although parent relationship difficulties have been most thoroughly studied in relation to youth behavioral problems, several studies indicate their relevance for internalizing problems in offspring (Rapee, 2012). In a small study of 35 adolescents (ages 11-15) whose parents divorced, youths whose parents engaged in postdivorce conflict reported higher rates of anxiety and withdrawal than those whose divorce was relatively low conflict (Long, Slater, Forehand, \& Fauber, 1988). In another study, improved motherreported marital quality was negatively associated with specific phobias in 5- to 6-year-old children (Peleg-Popko \& Dar, 2001). Research conducted by Cummings, GoekeMorey, and Papp (2003) suggested that youths' state anxiety was linked with parental aggression toward one another during conflict, whereas youths' trait anxiety was related to parents' fear, sadness, and lack of problem solving during conflicts (Du Rocher Schudlich \& Cummings, 2003). In perhaps the most extensive study on this topic, more than 1,200 adolescents completed retrospective reports of interparental violence during their childhood and were also assessed for current psychiatric diagnoses. Adolescent-perceived interparental violence during childhood was strongly associated with both depression and anxiety in adolescent participants (Fergusson \& Horwood, 1998). 


\section{Parent-level factors and child characteristics:} Considering gender and age

Evidence is equivocal regarding gender differences in the impact of parental psychopathology on child internalizing problems. In one clinic-referred youth sample, parental psychopathology was more strongly linked with internalizing problems in sons than in daughters (Schleider, Chorpita, \& Weisz, 2014), while other studies have observed the opposite pattern (Cortes, Fleming, Catalano, \& Brown, 2006; Lewis, Rice, Harold, Collinshaw, \& Thapar, 2011) or no differences by gender (see Connell \& Goodman, 2002, for a meta-analysis). Regarding child age, a meta-analysis found that associations between parent and youth internalizing symptoms were stronger in younger children, perhaps because parents exert their greatest influence when their children are very young (Connell \& Goodman, 2002). In contrast, other studies have found significant links between parent symptoms and adolescents' internalizing difficulties (Hammen, Hazel, Brennan, \& Najman, 2012; Hops, 1992). Overall, studies on this topic are limited in several respects; they often fail to differentiate between parent symptom type, parent diagnostic status (clinical vs. subclinical), and parent gender, all of which may obscure patterns of effects. Future studies accounting for these points may be better positioned to detect and parse possible moderation effects by child age and gender.

The literature is more consistent on family structure: across numerous studies, no significant gender differences have been detected in rates of child internalizing problems in single- versus dual-parent homes (for a review, see Kelly, 2000). However, gender and age differences have both been observed in effects of interparental conflict on child internalizing problems. For instance, a meta-analytic study found that, across 71 studies, exposure to interparental conflict predicted internalizing problems in older children more strongly than in younger children (Rhoades, 2008). The author suggests several possible reasons for this effect. For instance, very young children (under age 10) might lack the cognitive ability to generate, process, and ruminate on maladaptive cognitions following interparental conflict. Alternatively, it is possible that older children have simply had more exposure to interparental conflict, and the effects of these exposures might compound over time. Regardless, child age is an important consideration when examining relations between interparental conflict and child internalizing difficulties.

Differential effects of interparental conflict by gender have also been observed. One study found that marital discord, reported by mothers, predicted increased internalizing problems in girls, but not boys, from early to middle adolescence (Crawford, Cohen, Midlarsky, \& Brook, 2001). Other studies suggest more subtle gender differences: in an 8-year longitudinal study, marital conflict (severity of arguments) predicted internalizing problems in 10-year-old girls, whereas negative emotional aftermath of conflict (unresolved, lingering tension) increased internalizing problems for both boys and girls (Brock \& Kochanska, 2015). Thus, specific patterns of inter- parental conflict may be important to assess in understanding gender-specific symptom trajectories.

\section{Youth processes affected by parent-level factors.}

Attentional bias. Cognitive models of anxiety and emotional disorders propose that negative attentional biases, or tendencies to preferentially notice and focus on negative information, plays a central role in the onset and maintenance of youth anxiety (Shechner et al., 2014) and depression (Teachman, Joormann, Steinman, \& Gotlib, 2012). Attention filters and directs information processing; thus, youths with biases toward negative stimuli may experience negative thoughts more frequently and intensely, in turn conferring risk for internalizing problems. Two kinds of negative attentional biases have been identified as especially relevant: threat bias in anxiety, or excessive vigilance to potentially threatening stimuli, and sad bias in depression, or difficulty disengaging from negative emotional content (Sylvester, Hudziak, Gaffrey, Barch, \& Luby, in press). Several studies have reported heightened vigilance toward threat in anxious youths (Dalgleish et al., 2003; Roy et al., 2008), sad bias among depressed youths (Hankin, Stone, \& Wright, 2010), and bias toward both threatening and sad stimuli in youths with comorbid anxiety and depression (Harrison \& Gibb, 2014). In addition, some computer programs designed to reduce bias toward threat in anxiety and away from emotional stimuli in depression may alleviate internalizing symptoms in children and adolescents (Lowther \& Newman, 2014; Riemann, Kuckertz, Rozenman, Weersing, \& Amir, 2013; Shechner et al., 2014), suggesting the relevance of attentional biases to the maintenance of these disorders. However, other trials found no effect of such computer programs on children's internalizing problems (e.g., Eldar, Ricon, \& BarHaim, 2008; Pitica, Susa, \& Benga, 2010), suggesting that further research is needed to fully investigate the utility of this approach.

Parent-level factors may shape threat and sad biases in youths. For instance, parental psychopathology or interparental conflict may render life at home unpredictable and erratic, sensitizing youths to potential threat at any given time. Youths in these families may grow vigilant to parental arguments or shifts in a caregiver's emotions or behavior, eventually developing a bias toward possible and perceived threat. Similarly, these parent-level factors may contribute to sad bias in youths. It is likely that many youths might have trouble disengaging from adverse experiences involving parents. However, regularly witnessing parental arguments or emotional difficulties might condition some youths to be "prepared" for, and attend to, negative feelings and thoughts, eventually forming a bias toward negative emotional content. Thus, negative attentional bias may be one youth process through which parent-level factors shape the onset and maintenance of youth internalizing problems.

Consistent with this possibility, parental depression and anxiety are strongly linked to sad bias and threat bias in off- 
spring (for a review, see Gotlib, Joorman, \& Foland-Ross, 2014). Joormann, Talbot, and Gotlib (2007) found that never-depressed daughters of recurrently depressed mothers attended selectively to threatening facial expressions following a negative mood prime, whereas daughters with never-depressed mothers preferentially attended to positive facial stimuli. Other studies suggest that daughters of depressed mothers preferentially attend to sad stimuli (Kujawa et al., 2011; Taylor \& Ingram, 1999), that daughters of mothers with panic disorder exhibit biases toward physical health-related threat cues (Mogg, Wilson, Hayward, Cunning, \& Bradley, 2012), and that parental anxiety predicts stronger threat bias in youths with social, generalized, and separation anxiety disorders (Blossom et al., 2013). Attentional bias may also help explain links between parent-level factors and youth internalizing problems. For instance, youths who interpret interparental conflict as more threatening, or who report more selfblame during these conflicts, have shown greater increases in anxiety and depressive symptoms (Dadds et al., 1999; Jouriles, Spiller, Stephens, McDonald, \& Swank, 2000).

In sum, parent-level factors may help shape and maintain attentional biases in youths, and these biases may in turn predict anxiety and depressive disorders in youth (Harvey, Watkins, Mansell, \& Shafran, 2004; Reid, Salmon, \& Lovibond, 2006). Thus, parent-level factors may influence youth internalizing problems by increasing youths' tendency to attend to and perceive negative information in their environments. Beyond youth processes, interpersonal processes such as attachment, discussed below, may also help account for these relations.

Attachment. Attachment theory provides a prominent framework for understanding the development of anxiety and depression in youth. According to Bowlby (1980), early attachment patterns between youths and their caregivers play a vital role in both normal and abnormal development. Attachment patterns are thought to derive from the quality and the quantity of contact that youths have with parents (Ainsworth, Blehar, Waters, \& Wall, 1978). Parents who are sensitive in their caregiving and who react to their infant's needs appropriately tend to have youths who develop secure attachment (Wenar \& Kerig, 2000). Secure attachment is thought to affect the youth's adjustment, emotions, and ability to form trusting relationships with others.

However, when typical parent-youth bonding is disrupted in some way, insecure youth attachment patterns have been hypothesized to result. These patterns have been posited to serve as risk factors for numerous youth problems, including depression and anxiety (Bowlby, 1980; Cummings \& Cicchetti, 1990). Although insecure attachment does not cause youth internalizing problems, it may render certain adverse developmental trajectories more likely. Insecure attachment correlates strongly with youth depression (Abela et al., 2005; Irons \& Gilbert, 2005) and anxiety symptoms, especially reassurance seeking and worry (Muris \& Meesters, 2002; Muris, Meesters, van Melick, \& Zwambag, 2001). Insecure attachment patterns early in childhood also predict the development of depressive and anxiety disorders in adolescents (Lee \& Hankin, 2009).

Parent-level factors may strongly shape the development of secure attachment in youths. For instance, studies have found adverse effects of interparental conflict (e.g., hostility, aggression, and withdrawal) on youth attachment security (Cox, Paley, Payne, \& Burchinal, 1999; Sturge-Apple, Davies, \& Cummings, 2006). One such study found that greater interparental conflict before or after a child's birth predicted insecure infant attachment to parents (Owen \& Cox, 1997). In another study, both physical and psychological aggression between parents predicted insecure youth attachment with fathers (Laurent, Kim, \& Capaldi, 2008). These findings fit with Davies and Cummings' (1994) "emotional security hypothesis," which posits that youths seek emotional security and secure attachments through exposure to a trusting, stable interparental relationship. Interparental conflict can compromise the youth's confidence in parents as a secure base, increasing youth internalizing problems over time (Laurent et al., 2008)

Parental psychopathology, especially depression, has also shown cross-sectional and prospective links to insecure attachment in offspring (van IJzendoorn, Schuengel, \& Bakermans-Kranenburg, 1999). Symptoms including anhedonia, fatigue, and feelings of worthlessness may deplete parents of the psychological resources necessary for providing warmth and responsiveness, increasing risk for insecure youth attachment. Compared to nondepressed controls, new mothers with depression have been characterized as less engaged, more critical, less responsive, and more avoidant in observational and self-report studies (Gelfand \& Teti, 1990; Goodman, 1992). Bowlby (1973) hypothesized that such parenting behaviors may lead youths to view themselves as unlovable, and others, as rejecting and unpredictable. Similar processes may apply to parents with other types of psychopathology: youths of parents with eating disorders, substance use, anxiety, or bipolar I disorder show more attachment disturbances than youths with psychologically healthy parents, even after accounting for the effects of parent depression (Gaensbauer, Harmon, Cytryn, \& McKnew, 1984; ZahnWaxler, Cummings, McKnew, \& Radke-Yarrow, 1984).

Overall, research suggests that parent-level factors such as interparental conflict and parental psychopathology may increase risk for insecure attachment in youths. Thus, insecure attachment might be a second youth process through which parent-level factors predict the later development of youth internalizing problems. Building on the pathways described thus far, the following sections review dyad- and family-level factors, their links to youth anxiety and depression, and youth processes through which they may operate.

\section{Dyad-level factors}

We will focus on four dyad-level factors in the development and maintenance of youth internalizing problems: parenting styles, parental modeling, parental praise, and sibling relationships. First, we will outline evidence for each factor's 
relation to youth internalizing problems. We will then propose several youth processes that may account for these links.

Parenting styles. The effect of parenting on youth development has long been a topic of investigation for psychological scientists. Very early work in this area explored numerous parenting dimensions, including responsiveness versus unresponsiveness (Freud, 1933; Rogers, 1960), emotionally involved versus uninvolved (Baldwin, 1948), acceptance versus rejection (Symonds, 1939), and restrictiveness versus permissiveness (Becker, 1964). These studies found that youths whose parents provided them with warmth, independence, and firm behavioral control had greater competence, confidence, and social adeptness (Baldwin, 1948; Sears, Macoby, \& Levin, 1957). Subsequently, Diana Baumrind's observational research led to her identification of three parental typologies: authoritative, authoritarian, and permissive (Baumrind, 1971, 1978, 1989). Within this model, authoritative parents are warm, affectionate, supportive, and responsive; authoritarian parents are strict, demanding, and assert power when offspring misbehave; and permissive parents are excessively lax in expectations for youths' maturity and tolerance of misbehavior. Overall, authoritative parenting is linked with positive youth outcomes, whereas authoritarian and permissive parenting, marked by maladaptive levels of control and warmth, have shown links to negative youth outcomes (Baumrind, 1967; Spera, 2005). (However, these findings vary according to families' cultural and racial backgrounds; e.g., Leung, Lau, \& Lam, 1998.)

More recent studies have built on this early work, suggesting that specific styles of parenting are consistently, if modestly, associated with anxiety and depression in youths (McLeod, Weisz, \& Wood, 2007; McLeod, Wood, \& Weisz, 2007). One such parenting dimension, known as psychological control versus autonomy granting, has been identified as especially important to youths' risk for internalizing problems. Psychological control is a pattern of parenting behaviors marked by coercive, passive-aggressive, intrusive strategies to manipulate youths' thoughts, feelings, and activities (Barber, 1996; De Man, 1986). Psychologically controlling parents tend to prevent youths from developing independence and increase fear while decreasing perceived control (Chorpita \& Barlow, 1998; Rapee, 2001). Consistent with these theories, high parental psychological control correlates with low self-esteem and internalizing problems in youths (Barber, 1996; Nanda, Kochick, \& Grover, 2012). Further, high maternal psychological control predicts increases in adolescents' anxiety across 1 year (Schleider, Vélez, Krause, \& Gillham, 2014) and depressive symptoms 3 years later (Pettit, Laird, Dodge, Bates, \& Criss, 2001). Conversely, parents' encouragement of autonomy may augment children's perceived mastery of their environment, leading to fewer internalizing problems (Zalta \& Chambless, 2011).

Rejection versus acceptance is a second parenting dimension related to youth anxiety and depression. Parental rejection is marked by low levels of parental warmth, approval, and responsiveness toward offspring (Clark \& Ladd, 2000). This dimension was first identified by Ronald Rohner (1975), whose parental acceptance-rejection theory postulates that youths' psychological adjustment varies directly with their experiences of parental acceptance versus rejection. Rohner's model, and theories based on this foundation, hold that parental rejection contributes specifically to the development of anxiety and depression by increasing sensitivity to anxiety and threat, undermining self esteem, promoting a sense of helplessness, and prompting development of negative self-schemas (Garber \& Flynn, 2001; Hammen, 1992; Kaslow, Deering, \& Racusin, 1994).

Parental modeling: Links to youth anxiety. Parental anxious modeling refers to a parent's tendency to demonstrate anxious thoughts, feelings, or avoidant behaviors in front of the child (Drake \& Ginsburg, 2012). Parents who model anxious behaviors, often due to their own anxiety, may inadvertently teach youths to be anxious and avoidant (Beidel \& Turner, 1997; Bögels \& Brechman-Toussaint, 2006; Fisak \& Grills-Taquechel, 2007). Correlational studies suggest links between greater parent-reported anxious modeling and greater youth-reported fears in clinical (Muris, Bögels, Meesters, van der Kamp, \& van Oosten, 1996) and community youth samples (Muris \& Merckelbach, 1998; van Brakel, Muris, Bögels, \& Thomassen, 2006). Further, parental anxious modeling can increase youths' anxious behaviors very early in life. De Rosnay, Cooper, Tsigaras, and Murray (2006) found that infants demonstrated more fear and avoidance of a stranger when their mother had previously shown fearful (as opposed to friendly or neutral) behavior toward that stranger. Similarly, Gerull and Rapee (2002) found that toddlers demonstrated more fear and avoidance of stimuli paired with a negative (rather than neutral or positive) maternal facial expression. In the one study of 8- to 12-year-old youths, youths reported higher levels of anxiety and an increased desire to avoid a spelling test when their parents acted worried (as opposed to relaxed and confident) prior to the test (Burstein \& Ginsburg, 2010). These findings strongly suggest the power of parental modeling to shape youth anxiety and avoidance, increasing subsequent risk for anxiety symptoms and disorders (Fisak \& Grills-Taquechel, 2007).

Parental modeling: Links to youth depression. Evidence suggests that parental modeling can also shape depressive cognitions and symptoms. For example, infants of mothers with depression exhibit higher levels of withdrawal and irritability, both behaviors common in depressed parents during parent-infant interactions (Abrams, Field, Scafidi, \& Prodromidis, 1995; Murray \& Cooper, 1997). During interactions, infants and toddlers of mothers with depression display more negative and fewer positive emotions, vocalize less, and have less motor activity than those of nondepressed mothers (Dawson et al., 2003). Apart from interaction styles, parents may model negative cognitions about their own behavior to their offspring when adverse events occur (Hankin 
et al., 2009). Youths may observe the inferences their parents make and, over time, adopt similar maladaptive cognitions. In line with this theory, several studies show correlations between self-reported attributional inferences and negative cognitions made by mothers and their offspring (for a review, see Alloy et al., 2006). Alternatively, parents may model negative attributions about their children's behavior following adverse events, leading offspring to internalize similar attributions over time (Fincham \& Cain, 1986). Self-report and observational studies have shown links between self-reported inferences that parents make about their youths, and subsequently, those youths' own inferences about causes of events (Alloy et al., 2006; Mezulis, Hyde, \& Abramson, 2006).

Parental praise. Regardless of caregivers' parenting styles, virtually all parents offer feedback to their children in response to their successes and failures. Praise, perhaps the most common kind of parental feedback, can affect youths' motivation, affect, and academic outcomes (Brummelman, Thomaes, Orbio de Castro, Overbeek, \& Bushman, 2014; Cimpian, Arce, Markman, \& Dweck, 2007; Gunderson et al., 2013). Parents almost uniformly recognize the value of praise (Brummelman \& Thomaes, 2011). However, not all kinds of praise are equally helpful to youths. Recent studies suggest that some kinds of praise can lead to decreases in youth self-esteem and maladaptive motivational frameworks. In turn, these negative self-beliefs may contribute to the development and maintenance of internalizing problems.

One important praise dimension is outlined by the person praise versus process praise distinction (Dweck, 1975). Youths who receive more process praise, or praise for their effort and actions (e.g., "you worked hard"), may come to view their accomplishments as products of effort and practice, whereas youths who hear more person praise, or praise for inherent traits (e.g., "you're so smart"), may view the sources of their successes as fixed traits (Zentall \& Morris, 2010). Laboratory and observational studies suggest that person and process praise differently impact children's beliefs and behaviors, both in the short term (Cimpian et al., 2007; Corpus \& Lepper, 2007; Mueller \& Dweck, 1998) and over time (Gunderson et al., 2013). Specifically, person praise, unlike process praise, leads youths to avoid challenges and to withdraw in the face of failure, presumably because it teaches youths that ability is an unchangeable trait (Pomerantz \& Kempner, 2013). If youths receiving person praise try challenging tasks and fail, they might infer that they lack ability and avoid such tasks in the future.

Another kind of parental praise that has received empirical attention is inflated (i.e. disproportionately complimentary) praise. In general, praise conveys standards for future performance (Henderlong \& Lepper, 2002). Thus, when youths receive inflated praise (e.g., "that picture is amazingly beautiful" rather than "that drawing is beautiful"), they might feel pressured to continue meeting these exceedingly high standards in the future (Henderlong \& Lepper, 2002). Thus, inflated praise contains an implicit demand for continued ex- ceptional performance (Baumeister, Hutton, \& Cairns, 1990). If youths adopt these unrealistic performance standards for themselves, inflated praise might inadvertently increase their likelihood and fear of failure. For youths with existing vulnerabilities to internalizing problems, experiencing this failure may increase risk for symptomatology.

Sibling relationship quality. Most studies on dyad-level risk factors for youth anxiety and depression focus on the parent-youth relationship (Stocker, Burwell, \& Briggs, 2002). However, emerging evidence suggests the importance of dyadic sibling relationships to youths' risk for internalizing problems. Higher hostility and lower warmth within sibling dyads are associated with more anxiety symptoms, depressed mood, and lower self-esteem (Campione-Barr, Greer, \& Kruse, 2013; Padilla-Walker, Harper, \& Jensen, 2010). Further, observed and self-reported sibling conflict has predicted increases in youth anxiety and depression across 2- and 4year periods, above and beyond parenting and marital variables (Bank, Burraston, \& Snyder, 2004; Stocker et al., 2002). In contrast, sibling warmth can buffer the effects of stressful life events on internalizing problems: youths with an affectionate sibling relationship reported fewer depression and anxiety symptoms after stressful life events, such as the death of a loved one, than youths with a nonaffectionate relationship (Gass, Jenkins, \& Dunn, 2007). In other studies, youths living in homes with intense marital discord showed fewer subsequent internalizing symptoms in the presence of a positive sibling relationship (Jenkins \& Smith, 1990; Tucker, Finkelhor, Turner, \& Shattuck, 2013). Separately, among youths with clinically anxious parents, those reporting affectionate, low-conflict sibling relationships reported significantly fewer internalizing problems than youths reporting contentious, high-conflict sibling relationships (Keeton, Teetsel, Dull, \& Ginsburg, in press). Moreover, parental anxiety symptoms correlated with youth internalizing problems among youths with a poorer quality (low companionship or high conflict) sibling relationship, but not among youths with a higher quality sibling relationship. In addition, some research suggests that, for youths reporting low parent and peer support, sibling warmth buffers negative trajectories in self-esteem, loneliness, and depressive symptoms (East \& Rook, 1992; Milevsky \& Levitt, 2005). Thus, beyond supporting positive youth development in general, positive sibling relationships moderate the impact of negative life experiences on youth internalizing problems.

\section{Dyad-level factors and child characteristics: Considering gender and age}

Child age and gender are especially important to consider in the effects of parental psychological control. In preschoolaged children, this parenting style is associated primarily with externalizing problems (Hart, Nelson, Robinson, Olsen, McNeilly-Choques, 1998), with its relation to internalizing problems emerging during the preadolescent years (Barber, 
1996; Litovsky \& Dusek, 1985). In general, greater parental psychological control elicits child behaviors that are difficult for parents to control (Ballash, Leyfer, Buckley, \& WoodruffBorden, 2006). It is possible that the developmentally probable manifestation of such behaviors might be externalizing problems in younger children, shifting to internalizing distress as children's cognitive capacities mature.

In addition, parents' psychological control may have more negative effects for girls than for boys (Axinn, Young-Demarco, \& Ro, 2011; Pomerantz \& Ruble, 1998; Ruble, Greulich, Pomerantz, \& Gochberg, 1993). For instance, De Man (1986) found that, among older adolescents who reported having a psychologically controlling parent in childhood, girls reported elevated anxiety levels while men did not. Pettit et al. (2001) found that maternal psychological control predicted increases in anxiety and depression symptoms in girls, but not in boys, across the transition to early adolescence, particularly girls with subclinical symptoms at baseline. These findings suggest that perceived parental psychological control might uniquely facilitate internalizing problems in girls. To compound this differential gender effect, studies suggest that parents are more likely to exert autonomy-reducing behaviors, such as intervening rather than encouraging problem solving during challenging tasks, with daughters than with sons (Kerig, Cowan, \& Cowan, 1993; Zalta \& Chambless, 2012). Together, these patterns might jointly contribute to gender differences in internalizing disorders (Ruble et al., 1993).

In addition to psychological control, there is reason to believe that high parental criticism and low parental warmth might affect girls more adversely than boys during both childhood and adolescence. From a young age, girls tend to be more oriented toward relationships and gaining social approval than boys (Gabriel \& Gardner, 1999; Maccoby, 1990). As a result, they might be more sensitive to dyadic discord with family members. Girls are more likely than boys to have depressive reactions to interpersonal stressors and conflicts, including rumination, negative affect, and hopelessness, especially during adolescence, but as early as middle childhood (Hankin, Mermelstein, \& Roesch, 2007; NolenHoeksema \& Girgus, 1994; Rudolph, 2002; Rudolph \& Hammen, 1999; Shih, Eberhart, Hammen, \& Brennan, 2006). Future studies might explore this possibility by assessing children's sensitivity to interpersonal stressors concurrently with dyad-level factors and internalizing symptoms.

Finally, a meta-analysis of 34 studies found that child age, but not gender, moderated relations between sibling relationships and internalizing problems (Buist, Deković, \& Prinzie, 2013). Specifically, sibling conflict was more strongly linked with children's internalizing problems for sibling pairs with smaller age differences. This finding fits with earlier research suggesting that social influence increases as a function of similarity, including age (Andsager, Bemker, Choi, \& Torwell, 2006). The authors suggest that conflicts with a sibling close in age may be experienced as particularly intense; thus, they may be more likely to generate or sustain internalizing distress.
Youth processes affected by dyad-level factors.

Attentional and information processing bias. As discussed, youths with anxiety or depression are more likely than their psychologically healthy peers to attend to threatening information and to interpret ambiguous situations negatively (Cannon \& Weems, 2010; Waters, Mogg, Bradley, \& Pine, 2008). Early investigations suggested that parent-level factors may play a role in the development of youth attentional biases by modeling, via verbal and nonverbal communication, their own threat biases and avoidant tendencies (Chorpita, Albano, \& Barlow, 1996). For instance, Barrett, Dadds, Rapee, and Ryan (1996) presented clinically anxious and nonanxious youth with ambiguous situations and asked them to provide an interpretation, discuss it with their parent, and report their final solution for each situation. For anxious youths, avoidant responses increased significantly following discussion with a parent, and parents were more likely to reward and reciprocate avoidant responses. Thus, parental modeling through behavior and communication may contribute to transmission of threat bias, and subsequent anxiety, from parents to youths.

Negative parenting styles have also shown links to attentional biases linked with youth depression. Beck's theory of depression suggests that depressed or vulnerable individuals often exhibit cognitive information processing biases. In two independent youth samples, observed authoritarian and critical parenting was associated with youths' selective attention to angry faces (Hankin et al., 2009). This suggests that negative parenting may lead to biased information processing of socially relevant stimuli, which may, in turn, confer risk for depression.

Cognitive style and perceived control. Dyad-level factors might also influence youth internalizing problems by facilitating the formation of certain kinds of cognitive styles, defined as the habitual ways individuals account for events in their lives (Peterson \& Steen, 2002). Cognitive styles may become especially relevant for children's internalizing problems during preadolescence. At this developmental stage, understandings of why events occur tend to shift from "known" versus "unknown" (a categorization typical of 7- to 8-yearolds; Connell, 1985) to more nuanced self- and other-directed explanations (Nowicki \& Strickland, 1973). One well-studied cognitive style, attributional style, varies across three domains: internal versus external (viewing events as caused by the self or by external factors), stable versus unstable (viewing causes of events as unchangeable or changeable), and global versus specific (viewing causes of events as generalizable or isolated instances; Abramson, Seligman, \& Teasdale, 1978). Theory and empirical research suggests that negative (i.e., internal, stable, and global) attributional style mediates links between negative life experiences and youth internalizing problems (Garber \& Flynn, 2001; Turner $\&$ Cole, 1994). For instance, a child who views negative events as having stable, global causes may view a fight 
with her parent as resulting from a fixed difficulty that affects all parts of her life. This kind of negative bias toward interpreting events has prospectively predicted anxiety (Lau, Rijsdijk, \& Eley, 2006; Mezulis et al., 2006; Schleider, Vélez, et al., 2014) and depression in youths (Abela, 2001; Abela \& Sarin, 2002).

Related to negative attributional style, youths with low perceived control over their lives are more likely to experience internalizing problems (Chorpita, 2001; Weisz, Southam-Gerow, \& McCarty, 2001). Theoretical models posit that anxiety and depression exist on a shared dimension of distress reflecting the level of one's perceived control (Alloy, Kelly, Mineka, \& Clements, 1990): when an individual experiences uncertainty about his personal ability to control present and future events, anxiety will be the resulting affective state. When perceived control decreases further, the individual is thought to grow hopeless and certain of negative outcomes, leading to depression.

Parenting styles marked by rejection and psychological control correlate with and predict negative cognitive styles in youth, including both negative attributional style and low perceived control (Chorpita \& Barlow, 1998; Chorpita, Brown, \& Barlow, 1998; Lau et al., 2006; Mezulis et al., 2006). Further, the development of negative cognitive styles and low sense of control might explain links between specific parenting styles and youth internalizing problems. In one longitudinal study, early adolescents who perceived high maternal psychological control developed a more negative attributional style 6 months later, which in turn predicted increases in anxiety across 1 year (Schleider, Vélez, et al., 2014). In another study, which used a clinic-referred youth sample, associations between negative parenting styles (parent-reported overcontrol, neglect, and hostility) and youth anxiety and depression were mediated by youths' negative cognitive styles (McGinn, Cukor, \& Sanderson, 2005).

Based on these findings, youths with parents who exhibit high levels of psychological control or rejection might come to habitually view adverse situations as uncontrollable, and their causes as stable and global. Psychologically controlling parents are often harsh, intrusive, and guilt inducing, and parental rejection is characterized by low warmth and high criticism. Chronic exposure to these parenting behaviors may shape youths' beliefs about not only their parents but also the world around them. For instance, these youths may develop beliefs such as "I am never good enough" or "adults are mean no matter what I do." Such beliefs may affect youths' expectations for the future, possibly leading them to view the world as dangerous, anticipate negative outcomes, or doubt their ability to control negative events. Thus, certain parenting styles may foster the onset and maintenance of youth internalizing problems by reinforcing negative cognitive styles in youths.

In addition to certain parenting styles, parental modeling may also foster negative cognitive styles in youths, in turn exacerbating youth internalizing problems. As discussed, avoidance and withdrawal behavior in parents is often adopted by offspring. It is possible that, by witnessing a parent avoid challenging or unfamiliar situations, youths may come to believe that such situations are dangerous and uncontrollable. In turn, they may begin to exhibit similar avoidance behaviors, reinforcing their beliefs that they could neither control nor cope with unfamiliar situations on their own. Separately, negative cognitive styles may be "transmitted" directly from parents to youths through parental modeling of maladaptive thinking patterns. Recent evidence suggests that negative attributional styles can be transmitted from parents to youths via repeated parental modeling, even in the absence of clinically significant parental mood or anxiety disorders (Pearson et al., 2013).

Finally, several researchers have suggested that gender differences in maladaptive cognitive styles might explain gender differences in internalizing disorders, particularly in adolescence (for a review, see Hankin \& Abramson, 2001). Evidence is mixed as to whether girls consistently report more maladaptive cognitive styles than boys (for supporting evidence, see Leach, Christensen, Mackinnon, Windsor, \& Butterworth, 2008; Zalta \& Chambless, 2012; for conflicting evidence, see Gladstone, Kaslow, Seeley, \& Lewinsohn, 1997; Thompson, Kaslow, Weiss, \& Nolen-Hoeksema, 1998). However, this pathway is supported by a recent longitudinal study. Hamilton, Stange, Abramson, and Alloy (2015) found that interpersonal stress prospectively predicted higher levels of negative cognitive styles in girls than in boys, and this difference accounted for girls' greater increase in depressive symptoms during adolescence. Although these relations have not been tested in the context of anxiety, the finding does suggest that familial stress, which is inherently interdependent, may have especially adverse consequences for adolescent girls' internalizing problems by contributing to maladaptive cognitions.

Implicit theories. According to Dweck's (1975) achievement motivation theory, youths differ in their beliefs about the malleability of personal traits and abilities. These beliefs, called implicit theories, can influence youths' social, academic, and emotional functioning (Yeager et al., 2014). Implicit theories form a framework for interpreting and responding to adversity (Dweck, 1999). Individuals who hold incremental theories of personal traits, such as intelligence or personality, believe they can change those traits through effort. In the face of challenge, incremental beliefs promote persistence and creative problem solving, increasing the likelihood of desired outcomes. In contrast, youths with entity theories of personal traits view them as fixed and uncontrollable. Entity theories facilitate the belief that difficulties are a product of one's fundamental flaws, leading to hopelessness, fear, and low persistence following failure (Blackwell, Trzesniewski, \& Dweck, 2007; Burnette, O’Boyle, Vanepps, Pollack, \& Finkel, 2013; Erdley, Cain, Loomsis, Dumas-Hines, \& Dweck, 1997; Rudolph, 2010; Yeager et al., 2014). Further, a recent meta-analysis found consistent relations between entity theories and youth mental health problems of 
multiple types, including anxiety and depression, supporting the relevance of implicit theories to youth internalizing problems (Schleider, Abel, \& Weisz, 2015). This relation might be bidirectional; in some studies, entity theories have predicted increases in internalizing problems (Romero, Master, Paunesku, Dweck, \& Gross, 2014), while in others, internalizing problems led to stronger entity theories (Schleider \& Weisz, in press).

Across experimental and naturalistic studies, person praise has shown relations to entity theories in youths, while process praise has shown links to incremental theories (Cimpian et al., 2007; Zentall \& Morris, 2010). As one example, Mueller and Dweck (1998) found that youths who received process praise after completing a novel task ("You must have worked hard at these problems") subsequently sought out additional challenges and performed better on subsequent tasks. In contrast, youths who received person praise following the same task ("You must be smart at these problems") showed entity theory-consistent behaviors, including avoidance of challenges and declines in performance. Further, one naturalistic study found that the more person praise mothers provided their young children over a 10-day period, the greater offspring's increases in entity theories of intelligence and avoidance of challenging tasks (Pomerantz \& Kempner, 2013). Thus, patterns of person-focused praise from parents may facilitate youths' beliefs that personal traits are unchangeable, heightening risk for maladaptive setback responses and internalizing problems in the future.

Possible gender differences in this pathway are notable. For example, evidence suggests that boys are more likely than girls to receive praise for effort (i.e., process praise) from adults (Dweck, Davidson, Nelson, \& Enna, 1978) and that girls are more likely than boys to respond to stressors in entity theory-consistent ways (Alessandri \& Lewis, 1993; Dweck, 1986; Siegle, Rubenstein, Pollard, \& Romey, 2010). Further, in one recent study of early adolescents, entity theories of thoughts, feelings, and behavior were more strongly linked with mental health problems in girls than in boys, including internalizing distress (Schleider \& Weisz, 2016). Moreover, girls with greater baseline mental health problems were more likely to develop entity theories of feelings 6 months later. The possibility that maladaptive praise and entity theories may disproportionately relate to internalizing problems in girls merits additional exploration. Future research may clarify the consistency and developmental trajectory of these effects.

Some research also suggests that inflated praise might contribute to entity-theory consistent behavior, especially in youths already experiencing subclinical self-esteem difficulties. Adults generally recognize low self-esteem in youths as worrisome (Thomaes, Brummelman, Bushman, Reijntjes, \& Orobio de Castro, 2013). Both in and out of laboratory settings, adults are more likely to give praise, and especially inflated praise, to youths with low self-esteem than to youths with high self-esteem. Studies suggest that adults tend to believe they are being helpful to these youths by providing ex- aggerated praise (Hamilton \& Hunter, 1998). However, this assumption holds potential to backfire: Brummelman et al. (2014) found that inflated praise decreases challenge-seeking behavior in youths with lower than average self-esteem. The authors suggest that receiving inflated praise might trigger self-protectiveness in lower self-esteem youths, that is, a desire to continue appearing competent while trying not to reveal the deficiencies they perceive in themselves. Thus, for youths with existing emotional vulnerabilities, inflated praise might lead to behavior and thoughts consistent with entity theories of personal traits, potentially heightening risk for internalizing problems over time.

Emotion regulation skills. Emotion regulation has broadly been defined as the process of modulating the occurrence, form, intensity, or duration of internal states and physiological processes to accomplish one's goals (Thompson, 1994). Emotion regulation and its component skills represent core capacities that can foster typical, positive, or adverse developmental outcomes (Eisenberg, Spinrad, \& Eggum, 2010). Because anxiety and depression often involve difficulty controlling cognitions, attention, and emotions (Garnefski, Kraaij, \& van Etten, 2005), it is not surprising that poorer emotion regulation skills, measured via behavioral and self-report measures, predict and help maintain anxiety and depressive symptoms in youths (Carver, Johnson, \& Joormann, 2008).

Dyadic aspects of family process have strong potential to shape youths' emotion regulation skills, in turn affecting risk for internalizing problems (Morris, Silk, Steinberg, Myers, \& Robinson, 2007). To learn to flexibly, autonomously regulate their emotions, youths require opportunities to practice their emotion regulation skills: first with the guidance of parents, and ultimately, on their own (Grolnick \& Farkas, 2002). Thus, parental autonomy granting, attentiveness, and acceptance all facilitate youths' mastery of emotion-regulation skills. For example, when mothers are available for referencing in fear-inducing situations (versus unavailable such as reading a newspaper), youths show less distress and more engagement with the stimulus (Diener, Mangelsdorf, Fosnot, \& Kienstra, 1997). While parental attentiveness and guidance promote adaptive distress regulation, rejection may impede its development: adolescents with mothers who exhibited more "rejecting" responses to their positive affect, such as invalidating or dismissing, reported using more maladaptive emotion regulation strategies. Over time, their use of these strategies predicted increases in depression and anxiety symptoms (Yap, Allen, \& Ladouceur, 2008). However, when positive parental attentiveness becomes intrusiveness, youths may receive fewer opportunities to practice regulating emotions on their own and develop their emotion regulation skills. Several studies have supported this possibility: greater self-reported use of adaptive versus less adaptive emotion regulation strategies has mediated relations between paternal and maternal psychological control and subsequent depressive symptoms in youths ages 10-18 (Brenning, Soenens, Braet, \& Bal, 2012; Cui, Morris, Criss, Houltberg, \& Silk, 2014). 
In addition, relationships between siblings have great potential to shape youths' emotion-regulation abilities. It has been suggested that siblings provide a unique context in which youths can practice skills and behaviors learned elsewhere, such as emotion-regulation strategies. In doing so, siblings can either reinforce or discourage those same behaviors and skills (Parke \& Buriel, 2006). For example, in middle childhood and early adolescence, sibling relationships are generally high conflict (Brody, 2004), providing parents with frequent opportunities to scaffold youths' emotionalregulation strategies and skills. During later adolescence, siblings begin to spend more time interacting with each other than they do with their parents (Larson \& Richards, 1994), creating ample opportunities to practice regulating their emotions and resolving conflicts autonomously (Parke \& Buriel, 2006). For siblings with a supportive, warm relationship, conflicts or disagreement foster the formation of positive selfregulation strategies and coping skills, whereas siblings with a relationship marked by distance or aggression may not reap these benefits. In preschoolers, sibling relationships marked by warmth have shown links to self-regulation (Volling, McElwain, \& Miller, 2002). A more recent study found that adolescents' self-regulation skills prospectively mediated links between higher sibling relationship warmth and lower internalizing symptoms, controlling for parent-youth relationship quality (Padilla-Walker et al., 2010). These findings suggest that sibling affection might promote self-regulation in youths, in turn buffering risk for internalizing difficulties.

\section{Family-level factors}

We will focus on the roles of three family-level factors in the development of youth internalizing problems: family functioning, family stability, and parental differential treatment (PDT). Each factor is considered as it relates to the full family unit, rather than to parent-child dyads, as were discussed above.

Family functioning. Two prominent theories for assessing family functioning are the "enmeshment-disengagement" framework (Minuchin, 1974) and the "cohesion-adaptability" framework (Olson, Russell, \& Sprenkle, 1983). Both are relevant to understanding links between family functioning and youth internalizing problems. Minuchin's (1974) theory frames family functioning as a product of interpersonal boundaries among family members, ranging from diffuse or "enmeshed" boundaries to overly rigid or "disengaged" boundaries (Minuchin, 1974). The enmeshing pattern includes parents' attempts to "pull in" the youth to meet his or her needs, without respecting the youth's personal or psychological space ("spousification" or "parentification" of a child). Conversely, in the disengaged pattern, one family member dominates interactions, excludes other members, or makes unilateral decisions for the family unit. According to Minuchin, clear and appropriate familial boundaries are necessary for successful adaptation to changing intra- and extrafamilial demands.
Building on this conception, Olson et al. (1983) identified cohesion and adaptability as two fundamental dimensions of family functioning. Within this model, cohesion is defined as "the emotional bonding that family members have toward one another" (Olson et al., 1983, p. 60). As in Minuchin's model, low-cohesion families are disengaged, whereas high-cohesion families are enmeshed; moderate levels of cohesion characterize a well-functioning family (Olson et al., 1983). Separately, adaptability is defined as "the ability of the family system to change in its power structure, role relationships, and relationship rules in response to ... stress" (Olson et al., 1983, p. 60). This dimension ranges from rigid (very low) to chaotic (very high). Again, moderate adaptability is considered to characterize a well-functioning family.

Several studies have investigated relations of family enmeshment, disengagement, and adaptability to anxiety and depression in youths (Ginsburg, Riddle, \& Davies, 2006). Stark, Humphrey, Crook, and Lewis (1990) found that youths in Grades 4-7 diagnosed with an anxiety disorder, a depressive disorder, or both perceived their families as more enmeshed, more disengaged, and less supportive than did youths without a psychiatric disorder. Youths with comorbid anxiety and depression and their mothers reported the greatest family boundary disturbance. Moreover, in a study of adolescent school refusers with comorbid anxiety and depression, adolescents and their families described their family as low in cohesion and adaptability (Bernstein, Warren, Massie, \& Thuras, 1999). Adolescents reporting strongly disengaged families reported significantly more depressive symptoms than those reporting more connected families, and adolescents in extremely rigid families had higher somatic complaints.

The few prospective studies that exist on this topic have suggested that family functioning domains predict increases in youth internalizing problems. One such study suggested that low family cohesion and high disengagement predicted a fourfold increase in the emergence of depressive disorders in youths across a 10-year period (Nomura, Wickramaratne, Warner, Mufson, \& Weissman, 2002). Another study, using observational methods, suggested that high family disengagement during a youth's preschool years predicted the development of anxiety and depressive disorders in youths 5 years later. In this study, disengaged triadic interactions were characterized by low warmth or affection, as well as little or no eye contact and emotional responsiveness between family members. In the same study, enmeshment in family interactions during the preschool years predicted elevated levels of depression in middle childhood (Jacobvitz, Hazen, Curran, \& Hitchens, 2004).

Family stability. Another family-level factor linked to youth internalizing problems is family stability, defined as the predictability and consistency of a family's routines and activities (Israel, Roderick, \& Ivanova, 2002; Ivanova \& Israel, 2005). In a stable family environment, activities are pursued with regularity, and members are able to predict with some 
accuracy when and how events will occur. Family stability may manifest differently across families (Israel et al., 2002). For instance, one family may achieve stability by regularly eating meals together and following predictable bedtime routines. In contrast, another family may not eat together regularly, but may engage in enjoyable activities together on weekends and regularly spend time talking together.

Family stability during childhood relates to psychological well-being in young children (Markson \& Feise, 2000) and older adolescents (Fiese, 1992). Family stability has also protected against the development of youth anxiety and depression symptoms and predicted increases in self-esteem (Israel \& Roderick, 2001; Israel et al., 2002; Ivanova \& Israel, 2005). Overall, greater consistency and predictability of events and activities in a family of origin appear to be associated with fewer internalizing problems and greater well-being in youths.

$P D T$. Another dynamic that may influence youths' internalizing problems is PDT of different siblings within the same family unit. Specifically, PDT indicates that siblings perceive their parents to show more affection toward, have stricter rules for, or have more conflicts with one sibling than toward the other (Kowal, Kramer, Krull, \& Crick, 2002; Shanahan, McHale, Crouter, \& Osgood, 2008). The majority of parents show some degree of differential treatment (Atzaba-Poria \& Pike, 2008), often in response to differences in youths' personalities, gender, and age. Some degree of PDT may be necessary to responsive, appropriate parenting (Kowal \& Kramer, 1997). Nonetheless, youth-perceived PDT is consistently related to youth internalizing problems (Buist et al., 2013). Among youths reporting PDT in their families, disfavored siblings tend to show heightened depression and anxiety symptoms both concurrently and over time (Feinberg, Neiderhiser, Simmens, Reiss, \& Hetherington, 2000; Shanahan et al., 2008). These effects persist even after controlling for parent-youth relationship quality.

\section{Family-level factors and child characteristics: Considering age and gender}

Several components of family functioning have shown differential relations with girls' and boys' internalizing problems, in both young children and older adolescents. Jacobvitz et al. (2004) found that higher levels of observed enmeshment in families of 24-month-old children predicted increased depression in girls, but not boys, 5 years later. Consistent with this result, a separate study found that improvements in family adaptability buffered against increases in internalizing distress in girls, but not in boys, during the transition from high school to college (Moreira \& Telzer, 2015). These findings fit with evidence suggesting that girls' well-being may be more dependent than boys' on the quality of their family relationships, even as they enter young adulthood (Fuligni \& Masten, 2010; Telzer \& Fuligni, 2013). However, at least one study has found the opposite gender effect. In a study by Kivisto, Welsh, Darling, and Culpepper (2015), higher family enmeshment predicted greater increases in negative mood and emotion dysregulation during a lab-based stressor in boys than in girls. The authors suggest that, because girls are socialized toward attunement to the family's emotional climate, family enmeshment might fit with emotion socialization practices for girls. For boys, however, enmeshment may be more counter to typical emotion socialization practices, thus causing them greater internalizing distress. Both possibilities merit investigation in future studies on this topic.

Effects of PDT on internalizing problems may vary by both child gender and age. In Buist et al.'s (2013) meta-analysis, associations between PDT and internalizing problems were strongest for studies with higher percentages of brother pairs. Thus, boys are more likely to experience internalizing distress if they believe they are treated differently by their parents, perhaps due to boys' greater socialization toward competitiveness compared to girls (Carter, 2014). In addition, PDT showed stronger links to children's internalizing problems among younger children than for adolescents. Because of their increased focus on peers (Steinberg \& Monahan, 2007), adolescents may be less aware of PDT compared to their younger counterparts, buffering its adverse effects.

Finally, investigators have observed gender differences in the effects of family stability, rituals, and traditions on internalizing problems during both childhood and adolescence. For example, one study found that the frequency of family rituals, specifically, family dinners, were associated with lower internalizing problems in girls but unrelated to such problems in boys (Eisenberg, Olson, Neumark-Sztainer, Story, \& Bearinger, 2004). In another study, fathers' reports of more frequent family mealtimes were linked to lower anxiety and depressive symptoms in first-grade daughters, but not sons (Yoon, Newkirk, \& Perry-Jenkins, 2015). Girls tend to spend more time than boys engaging in organized family activities, communication, and traditions throughout adolescence and young adulthood (Fuligni \& Masten, 2010). Family stability has been linked to positive outcomes in boys, as well, but outcomes in categories that appear to be separate from internalizing difficulties (e.g., physical health and social competence; Guidubaldi, Cleminshaw, Perry, Nastasi, \& Lightel, 1986).

\section{Youth processes affected by family-level factors.}

Attachment. Although attachment theory has historically focused on the dyadic parent-youth relationship, it is reasonable to expect that family-level factors might have a powerful impact on the development of secure attachment in youths (Bögels \& Brechman-Toussaint, 2006; Stevenson-Hinde, 1990). For example, work by Michuchin (1974) and Olson et al. (1983) suggest that clear, appropriate boundaries between family members allow youths to develop independence while still sensing familial warmth. In such an environment, research has found that youths are more likely to develop secure attachment (Harvey \& Byrd, 2000), perhaps because they trust that their family will respond sensitively and consis- 
tently to their needs. Conversely, family environments marked by disengagement, enmeshment, and chaotic relationships have shown associations with attachment insecurity in youths (Mikulincer \& Florian, 1999; Wilson et al., 2000). Future longitudinal research may help clarify the nature and consistency of this association, for instance, by comparing high disengagement, enmeshment, and chaos as unique and joint contributors to children's attachment security.

Most research on links between familial factors and attachment has focused on the roles of parent- and dyad-level factors, rather than family-level factors, on subsequent youth outcomes (Bögels \& Brechman-Toussaint, 2006). However, one study found that the high enmeshment, low responsiveness, and high unpredictability explained up to $16 \%$ of variance in youths' maladaptive attachment style, controlling for parent- and dyad-level factors (parenting styles and parental attachment; Mikulincer \& Florian, 1999). Separately, Wilson et al. (2000) found that high familial adaptability, predictability, and cohesion, measured in the third trimester of pregnancy, predicted secure infant at 1 year of age. Accordingly, the theoretical links discussed above merit further empirical exploration. Future studies may continue testing whether family-level factors affect youth attachment independently of parent- and dyad-level factors, or whether aspects of family process might merely be reflective of the quality of parent-youth interactions.

Cognitive styles and perceived control. Family-level factors might influence youth internalizing problems by facilitating the formation of certain kinds of attributional styles and perceptions of control. Family stability during childhood might serve as a protective factor in this regard. First, family stability may provide youths with a sense of predictability over family activities, relationships, and patterns, as well as opportunities to exert control over the immediate environment. Second, observing parents and siblings establishing and maintaining routines may solidify youths' beliefs about the controllability of events, situations, and behavior. Youths in these families may also come to believe that events are changeable rather than stable, and that setbacks do not necessarily generalize to all aspects of their lives. Thus, family stability might protect against youth internalizing problems by strengthening personal control and fostering adaptive interpretations of challenging events.

In line with these possibilities, Ivanova and Israel (2005) found that family stability not only correlated with more positive attributional styles but also moderated links between negative attributional style and depressive symptoms in older adolescents. Specifically, among those reporting high levels of family stability, negative attributional style showed no association with depressive symptoms (Ivanova \& Israel, 2005). In other words, family stability early in life appeared to buffer against the development of negative attributional style, which has shown robust relations with depression in other prior work. In addition, a separate study found that youths' perceived control mediated links between high family stability and lower symptoms of both anxiety and depression (Sokolowski \& Israel, 2008). Taken together, findings support the theory that family stability may aid in the development of perceived control in youths, as well as adaptive interpretations of setbacks, protecting against youth internalizing problems over time.

Conversely, certain patterns of family functioning may contribute to the emergence of less adaptive cognitive styles in youth. For instance, in high-enmeshment families, parents commonly express to youths that they are responsible for their family's happiness. In turn, youths will often attempt to please their parents and siblings in order to maintain their well-being (Jacobvitz et al., 2004). This dynamic may diminish youths' perceived control over time: regardless of their efforts, youths will not consistently be able to influence their family members' emotions, thoughts, and behavior. In this way, family enmeshment may exacerbate feelings of hopelessness in youths, leading them to interpret adverse events as due to stable, global, and internal factors (e.g., "It will always be my fault that my family is unhappy"). Similarly, youths in highly rigid families may experience repeated losses of personal control, receiving few opportunities to exercise independence from their families. These youths may eventually feel hopeless to change the limits imposed on their lives, heightening risk for anxiety and depressive symptoms. Thus, family enmeshment and rigidity may relate to youth internalizing problems through the development of youths' negative cognitive styles.

Recent work suggests that family functioning and stability might be especially relevant for girls' cognitive styles and, in turn, their risk for internalizing problems. Several studies have suggested that girls' greater internalizing symptoms compared to boys might result from their greater exposure and sensitivity to interpersonal stressors, particularly those that are dependent on (rather than independent of) their behaviors or traits (Hankin et al., 2007; Rudolph, 2002; Stange, Hamilton, Abramson, \& Alloy, 2014). As examples, interpersonal dependent stressors would include family conflict or arguments with peers, whereas the death of a loved one would be an interpersonal independent stressor. Hamilton et al. (2015) observed that interpersonal dependent stressors predicted greater increases of maladaptive cognitive styles in girls than in boys, which helped account for gender differences in depression over time. Ongoing problems in familylevel factors, including enmeshment, disengagement, or instability, may act as interpersonal dependent stressors that may disproportionately increase girls' risk for internalizing problems. This risk may be greatest for girls during early adolescence, when maladaptive cognitive styles tend to emerge and solidify (Paikoff \& Brooks-Gunn, 1991).

Sibling comparison. Social comparisons between siblings may play a key role in relations between PDT and the emergence of youth internalizing problems. According to Festinger's (1954) social comparison theory, people tend to evaluate themselves based on comparisons with others, especially 
those who are physically proximate and similar to themselves. In line with this theory, youths regularly compare themselves to others, and these comparisons form a foundation for self-concept and self-esteem (Harter, 1993). Due to similarity and proximity, these comparisons are especially likely to occur between siblings, and in the presence of PDT, they are often negative. For instance, if one parent is more attentive to one sibling than to the other, the second sibling may conclude that she is at fault for this discrepancy, because "my sibling must be nicer than I am; I must not be nice enough" (Buist et al., 2013; Feinberg et al., 2000). Negative social comparisons between siblings may therefore cause feelings of unfairness, personal insecurity, and worry, even for "favored" siblings, who may develop feelings of guilt or fear of status loss (Boyle et al., 2004). A recent meta-analysis found that higher youth-perceived DPT was linked to greater youth internalizing problems, particularly in pairs of brothers, regardless of youths' self-perception as a favored or "disfavored" sibling (Buist et al., 2013).

\section{Relations and interactions among parent-, dyad-, and family-level factors}

Thus far, we have outlined how individual factors at the parent, dyad, and family levels might influence youth processes and, in turn, youth internalizing problems. However, it is equally important to consider how the triadic model may encourage exploration of these factors' joint effects on youth outcomes. Considered individually, none of the risk and maintenance factors reviewed have large associations with youth anxiety or depression. Table 1, which lists meta-analytic effect sizes $(r)$ of relations between many factors reviewed and youth internalizing dysfunction, shows that effects are generally small, with a few approaching the medium range. Thus, it is important to consider applications of multiple or $\mathrm{Cu}$ mulative risk models, which argue that children's developmental outcomes are better predicted by examining the accumulation of risk factors rather than focusing on the adverse consequences of singular indicators (Evans, 2003).

Despite the modest influences of each individual factor, it is rare for any familial stressor to occur in the absence of any others. Although precise rates of co-occurrence have not been documented, empirical research strongly supports the spillover hypothesis with regard to familial stressors: that is, difficulties in one family system (e.g., the marital dyad) tend to be transferred to other, related systems (e.g., the parent-child relationship; parental stress and psychopathology; Repetti, 1987). For instance, youths who grow up in homes with a depressed or anxious parent also tend to be exposed to greater stress (e.g., rejection, abuse, or marital discord) than children of psychologically healthy parents (Avenevoli \& Merikangas, 2006). Further, single parents tend to experience higher rates of stress and symptomatology than do parents in intact families, and their offspring may have less exposure to a healthy second caregiver (Connell \& Goodman, 2002; Schleider, Chorpita, et al., 2014). Parent- and dyad-level stressors also tend to occur simultaneously: a meta-analysis of 68 studies found that more negative parent-child relationships were strongly associated with more negative marital relations (Cohen $d=0.46$; Erel \& Burman, 1995). Similarly, parents' psychopathology can have a marked effect on the kinds of parenting styles they are likely to adopt. Interactions between depressed mothers and their offspring tend to be characterized by greater inconsistency, criticism, more negativity, and less involvement than matched controls (see Goodman \& Gotlib, 1999). Similarly, anxious mothers tend to show less warmth and encouragement and are often more critical, catastrophic, and less granting of autonomy during interactions with their children (Dumas, LaFreniere, \& Serketich, 1995). In addition, family-level factors can relate to variables on all other levels. Higher levels of PDT, for example, tend to be accompanied by more interparental discord (Deal, 1996; Yu \& Gamble, 2008) and less positive sibling relationships (Stocker, Dunn, \& Plomin, 1989).

Familial stressors' co-occurrence has important implications for research on predicting and reducing youth internalizing problems. Specifically, this co-occurrence highlights the need for improved conceptualization and modeling of how different familial stressors shape one another and, in turn, youth processes and outcomes. Typically, cumulative risk is conceptualized in terms of the number of stressful events a youth or family has encountered (Johnson, 1982). Consistent with the idea of "pileup" (McCubbin \& Patterson, 1983), this independent-additive model assumes that individual familial risk factors operate in a cumulative, linear pattern to place youths at increasing risk for internalizing problems. Although this approach has value, it precludes the possibility of finding more complex and potentially more descriptive risk patterns, for instance, interactive or exponential models (Gerard \& Buehler, 1999; Hodges, Tierney, \& Buchsbaum, 1984). Empirically comparing these risk patterns may point toward the factor, or network of factors, most central to reducing youth anxiety and depression. In the following section, we outline the triadic model's implications for preventing and treating youth internalizing problems, as well as strategies for translating models of cumulative risk into relevant longitudinal and intervention research.

\section{Implications for Intervention}

The goal of the triadic model of family process is to organize theory and evidence around modifiable, transdiagnostic factors that can contribute to youth internalizing problems. Ultimately, we hope the model may provide an empirical framework for researchers to identify ways to enhance treatment and prevention programs for youth internalizing problems. In the following sections, we outline some of the model's implications for intervention delivery and design.

\section{Broaden intervention delivery approaches: Parent-, dyad-, and family-focused models}

By involving family members in youth interventions in ways that explicitly address parent-, dyad-, or family-level factors, 
Table 1. Meta-analytic associations with youth internalizing problems and parent-, dyad-, and family-level factors

\begin{tabular}{|c|c|c|}
\hline & $r^{a}$ & References \\
\hline \multicolumn{3}{|c|}{ Parent-Level Factors } \\
\hline \multicolumn{3}{|l|}{ Parental psychopathology } \\
\hline Parental depression & $.14-.23$ & Goodman et al., 2011; \\
\hline Parental anxiety & .16 & Connell \& Goodman, 2002 \\
\hline Parental substance use & $.11-.12$ & \\
\hline \multicolumn{3}{|l|}{ Interparental interaction } \\
\hline Interparental conflict & .19 & Teubert \& Pinquart, 2010 \\
\hline \multicolumn{3}{|l|}{ Single vs. dual-parent home } \\
\hline (divorced vs. intact families) & .21 & Amato, 2001 \\
\hline \multicolumn{3}{|c|}{ Dyad-Level Factors } \\
\hline \multicolumn{3}{|l|}{ Parenting styles } \\
\hline Rejection (vs. warmth) & .20 (anxiety), .28 (depression) & McLeod, Weisz, \& Wood, 2007; \\
\hline \multicolumn{3}{|l|}{ Psychological control } \\
\hline (vs. autonomy granting) & .25 (anxiety), .23 (depression) & McLeod, Wood, \& Weisz, 2007 \\
\hline Parental modeling & Unknown & No meta-analyses exist \\
\hline \multicolumn{3}{|l|}{ Sibling relationship quality } \\
\hline Sibling warmth & -.12 & Buist, Deković, \& Prinzie, 2013 \\
\hline Sibling conflict & .27 & \\
\hline \multirow[t]{2}{*}{ Parental feedback (praise) } & Unknown & No meta-analyses exist \\
\hline & Family-Level Factors & \\
\hline \multicolumn{3}{|l|}{ Family functioning } \\
\hline High cohesion/enmeshment & .21 & Teubert \& Pinquart, 2010 \\
\hline Family stability & Unknown & No meta-analyses exist \\
\hline Differential treatment of siblings & .14 & Buist et al., 2013 \\
\hline
\end{tabular}

Note: Based on Cohen's (1988) guidelines, the effect size $r$ is small when $\geq .10$, medium when $\geq .24$, and large when $\geq .37$.

${ }^{a}$ The meta-analytic association $(r)$ with youth internalizing problems.

interventions may harness the influence of these factors to enhance youth internalizing trajectories. Below, we review examples of intervention programs for youth internalizing problems that demonstrate the feasibility and effectiveness of this approach. Elements of the triadic model might inform efforts aimed at enhancing, combining, or designing similar protocols.

Examples of interventions targeting parent-level factors. Interventions for youth internalizing difficulties may target families with parent-level challenges, such as parental mental illness. One approach is to conduct interventions directly with parents experiencing mental health problems with the goal of preventing internalizing difficulties in their offspring. Seigenthaler, Munder, and Egger (2012) conducted a meta-analysis of such interventions; they identified 13 randomized control trials (RCTs) of preventive programs for youths with a mentally ill parent. Most of these programs targeted parents with depression, almost all were parent focused (i.e., youths were not active participants), and all involved cognitive, behavioral, and/or psychoeducational strategies to enhance parenting skills. For youths whose parents participated in one of these programs, risk of developing the same mental illness as their parent decreased by $40 \%$, relative to comparison groups, and youth internalizing symptoms decreased by 0.2 $S D$ overall. Many of these programs also reduced symptoms in parents themselves, which might have contributed to positive youth outcomes. Another strategy for preventing problems in youth, targeting parent-level factors, is to focus on reducing parental anxiety and depression (Garber, 2006). Little research has examined this possibility directly, although some evidence suggests that decreasing parental depression is associated with a commensurate decrease in internalizing symptoms in offspring (see Garber, 2006). In a similar vein, it is possible that interventions aimed at reducing conflict between parents might have positive impacts on youth internalizing symptoms. However, to our knowledge, this possibility has not been empirically explored.

Examples of interventions targeting dyad-level factors. Interventions can focus on youths' interactions with parents or siblings to ameliorate dyad-level difficulties and, in turn, youth internalizing problems. For instance, in recent years, a handful of research groups have adapted and modified parentchild interaction therapy (PCIT), originally developed to treat externalizing problems in young children, to treat various early internalizing problems using a set of related protocols 
(for a review, see Carpenter, Puliafico, Kurtz, Pincus, \& Comer, 2014). As in traditional PCIT (Eyberg \& Funderburk, 2011), these protocols use live parent coaching, delivered through a bug-in-the-ear receiver from a therapist behind a one-way mirror, to reshape parent-youth interaction patterns associated with internalizing symptoms. In a recent RCT of PCIT adapted for separation anxiety in 4- to 8-year-olds, $73 \%$ of youths assigned to adapted PCIT no longer met criteria for a diagnosis of specific anxiety disorder, compared to $0 \%$ of youths in the control group (Pincus et al., 2010). In an efficacy study of another PCIT adaptation for 3- to 8year-olds experiencing generalized, social, or separation anxiety, $86 \%$ of treatment completers no longer met criteria for an anxiety disorder posttreatment (Puliafico, Comer, \& Albano, 2013). Another PCIT adaptation, called PCIT-Emotional Development (ED), aims to reduce youth depressive symptoms by enriching parents' and youths' interactions surrounding emotion identification, understanding, and regulation (Luby, Lenze, \& Tillman, 2012). Parents are also taught to model positive emotion regulation strategies. In an RCT with 54 youths (ages 3-6), those in the PCIT-ED group showed greater reductions in depression and greater improvements in emotion labeling skills than those in an active control group (Luby et al., 2012). Further, mothers participating in PCIT-ED experienced greater decreases in their own depressive symptoms and parenting stress compared to those in the control group, demonstrating the potential of dyadbased interventions to positively affect family factors at multiple levels.

Parent-youth dyads may also be targeted in interventions for older youths, such as adaptive inferential feedback training (Dobkin et al., 2007; Panzarella, Alloy, \& Whitehouse, 2006). Adaptive inferential feedback is a cognitive technique that involves teaching parents and youths to respond to each other's maladaptive thoughts by promoting evidence-based thinking. Preliminary evidence suggests that this approach facilitates reductions in depression and anxiety symptoms in adolescents (Dobkin et al., 2007; Panzarella et al., 2006). In addition, an intervention targeting parental praise styles might have positive effects on youth internalizing dysfunction. In such a program, parents might receive information and coaching on adaptive praise strategies, learning to differentiate "process" from "person" praise, to use specific, action-focused praise statements toward their offspring, and to limit exaggerated praise. Although an in-depth, praise-focused intervention has not been empirically tested, it may have potential to complement concurrent efforts to prevent or reduce youth internalizing difficulties.

Beyond parent-youth interactions, interventions may also facilitate positive sibling relationships to reduce youth internalizing problems. However, few evidence-based approaches exist for strengthening relationships between siblings, and only one study has explored the impact of such a program on youth internalizing difficulties (Kramer, 2004). This program, called Siblings Are Special (SAS), aims to prevent youth emotional and behavioral problems by enhancing youths' social-emotional competencies in the context of their sibling relationships (Feinberg et al., 2013). It also aims to strengthen parents' ability to manage sibling relationships. Results have supported the intervention's promise: compared to youths in a psychoeducation control condition, youths in SAS reported significantly fewer internalizing problems at posttreatment. Improvements also extended to other dimensions, based on parent report, including enhanced sibling relationship quality, lower parental stress, and higher parental efficacy regarding the ability to parent siblings. The effect of SAS on parent-focused variables is consistent with research showing secondary gains for programs focused on enhancing sibling relationships. For instance, one study found that mothers and fathers whose offspring participated in a sibling-relationship-building program showed increases in their own emotion regulation skills (Ravindran, Engle, McElwain, \& Kramer, 2015). Although additional trials with both clinical and nonclinical samples will be necessary to ascertain sibling-based programs' effects, the SAS study supports the promise of incorporating siblings into interventions for youth internalizing problems.

Examples of interventions targeting family-level factors. Interventions for youth internalizing dysfunction can include multiple family members, targeting family-level risk factors or challenges. One example of such an intervention is attachment-based family therapy (ABFT), which is a protocol that aims to strengthen family relationships, identify family conflicts, improve family functioning, and ultimately, decrease depression and suicidality in adolescents. ABFT includes adolescent-only, parents-only, and family sessions, in which adolescents and parents learn new communication, problemsolving, and coping skills (Birmaher, Brent, \& AACAP Work Group on Quality Issues, 2007). In an RCT, adolescents with depression assigned to ABFT, compared to a wait-list control, demonstrated greater improvements in clinician-rated depressive symptoms, self-reported anxiety, and family conflict (Diamond, Reis, Diamond, Siquelnd, \& Isaacs, 2002). Another RCT compared ABFT's efficacy with that of usual care (in this case, facilitated referrals with ongoing clinical monitoring) in treating 66 youth with depressive symptoms and suicidal ideation. Youths receiving ABFT demonstrated faster rates of improvement in suicidal ideation, depressive symptoms, and anxiety symptoms, with benefits maintained at 3-month follow-up assessment (Diamond et al., 2010). Another trial of ABFT targeted adolescents with anxiety disorders supports a combined CBT and ABFT for adolescents with anxiety disorders (Siqueland, Rynn, \& Diamond, 2005). Specifically, this RCT compared CBT or CBT plus attachment-based family therapy (CBT-ABFT). Results suggested that both interventions reduced symptoms of anxiety and depression at posttreatment and follow-up. Taken together, results suggest that interventions focused on family-level challenges can effectively reduce internalizing symptoms and disorders in youths.

According to a recent review of family-based treatments for youth psychopathology (Kaslow, Broth, Smith, \& Collins, 
2012), only one study has assessed the effectiveness of family-based treatment for depression in younger children. This program, Stress-Busters, is a school-based family education intervention that combines teaching cognitive behavioral, skill-building strategies for youth, sharing those skills with parents, and conducting family to promote a more supportive family environment (Asarnow, Scott, \& Mintz, 2002). Postintervention, fourth through sixth graders who received Stress-Busters had significantly higher satisfaction and fewer depressive symptoms, negative cognitions, and maladaptive coping responses than those in the wait-list control.

Several RCTs have supported family-based cognitive behavioral therapy for anxiety disorders in youths. Wood, Piacenrini, Southam-Gerow, Chu, and Sigman (2006) compared a family-based version of the cognitive behavioral Building Confidence Program (FCBT) and a traditional, individual child-focused version (ICBT) for 6- to 13-year-olds with separation, generalized, or social anxiety disorder. The FCBT group, which received supplementary training in parentyouth communication, had greater reductions in youth anxiety per clinician and parent reports. Kendall, Hudson, Gosch, Flannery-Schroeder, and Suveg (2008) compared FCBT to ICBT and a family-based psychoeducational control group for 7- to 14-year-olds with specific anxiety disorder, generalized anxiety disorder, or social phobia. Although children improved in all three conditions, FCBT and ICBT reduced anxiety symptoms more than controls (through 1-year followup), and FCBT was superior to ICBT when both parents also had anxiety disorders. Thus, FCBT and other interventions targeting family-level factors may be especially helpful for families experiencing additional stressors at the parent or dyad levels.

\section{Next steps for treatment delivery}

The studies outlined above, as well as others not described here (for a review, see Young \& Fristad, 2015), strongly support addressing parent-, dyad-, and family-level factors in interventions for youth internalizing problems in a more comprehensive, structured way. However, they also highlight areas in need of further research and consideration. For example, very few interventions for youth internalizing problems, even those that are "family based," include siblings in their protocols. Given preliminary evidence that sibling-focused psychosocial programs can benefit youths' internalizing trajectories, involving siblings in interventions may present a new way to enhance youth outcomes. Similarly, several other family factors identified in our model are rarely addressed in interventions for youth internalizing dysfunction. Training in parental praise, for instance, is a core component of behavioral parent training for youth conduct problems but is seldom included in youth internalizing protocols. However, given the evidence reviewed, learning the differences and possible effects of person, process, and inflated praise might help parents better support youths with internalizing difficulties. Further, some evidence suggests that behavior parent training used for youth externalizing problems may be a promising treatment strategy for reducing depression symptoms in children (Ekshtain, Kuppens, \& Weisz, in press).

In addition, existing interventions address a wide variety of familial factors: some address parenting styles and modeling; others, parental mental illness; and some, family functioning and stability. However, across youths and families, the factors most important to target in treatment will differ. For instance, one youth might have strong dyadic relationships with her parents and siblings individually, but family stability might be low, or interparental conflict might be a concern. For another youth, family- and parent-level factors might be intact, but parents might benefit from training in adaptive praise and modeling. The development of a structured assessment of parent-, dyad-, and family-level factors might help clinicians determine which aspects of family environment might be most important to address, and thus assist them in personalizing treatment to fit individual youths and families. Such an assessment might involve a self-report inventory, completed separately by parents and youths, or an adjunct to a diagnostic interview. Either may inform which familial factors will be most helpful to target in treatment, and what kind of intervention delivery model might best fit a particular youth's family context. In addition, such an assessment might identify family strengths at different levels, for instance, an especially strong sibling relationship, that might be harnessed to support intervention goals.

Further, as reviewed in previous sections, child gender and age can have considerable impact on the relevance of any given familial stressor to the onset and maintenance of internalizing problems. These effects may suggest intervention strategies most likely to benefit certain youth populations. For example, strengthening sibling closeness, reducing sibling conflict, and minimizing PDT might prove especially helpful for younger children, boys with brothers, or those with a sibling close in age, all factors that may amplify links between sibling relationships and internalizing difficulties (Buist et al., 2013). In contrast, programs designed to strengthen adaptive attributions following familial stress might be most effective for children ages 10 and older, once their capacity to reflect and understand the causes of life events is more developed. Regarding the role of gender, several familial factors (e.g., interparental conflict, parental psychological control, and family functioning) and youth processes reviewed (e.g., entity theories and maladaptive cognitive styles) may be linked to internalizing problems in girls more strongly than in boys, particularly during the adolescent years. A common explanation for these differences relates to girls' greater socialized interpersonal orientation, as well as their relatively high sensitivity to interpersonal dependent stressors, as compared to boys (Hamilton et al., 2015; Rudolph, 2002; Stange et al., 2014). Thus, strategies focused on increasing perceived control and adaptive cognitions following stressful familial experiences, for example, viewing a parent's behavior as psychologically controlling or one's family as highly disengaged, might be particularly powerful 
for adolescent girls. Coupled with thorough assessment of familial stressors and strengths, these gender- and agespecific patterns may inform providers' selection of treatment targets and strategies.

Finally, as discussed, familial stressors at the parent, dyad, and family levels are strongly interrelated and rarely occur alone. Therefore, it will be important to examine whether and when intervening on one familial stressor has positive, "spillover" effects on others, and in turn on youth outcomes over time. As a theoretical example, intervening on parental depression might do more than reduce a parent's symptoms: it may also provide parents with the emotional resources to relate more attentively to their spouse and children, thus strengthening the family's functioning as a unit. Improvements in diverse aspects of family process might have additive or even multiplicative effects on positive youth outcomes. Some research supports this hypothesis. Based on findings from the Child/Adolescent Anxiety Multimodal Treatment Study, in which all youths received some form of individual treatment for clinical anxiety, improvements in family functioning, and caregiver stress jointly led to greater improvements in youth anxiety symptoms, especially for youths with psychologically distressed parents (Schleider, Ginsburg, et al., 2015). Although this trial did not test a family-focused intervention, findings suggest that improvements in multiple familial domains, in this case, parent- and familylevel factors, can strengthen youth treatment response. Accordingly, future intervention trials should assess multiple aspects of family process across intervention periods. This strategy might help determine familial targets that have the strongest spillover effects to other domains of family stress and, in turn, most broadly support reductions in youth internalizing problems.

In summary, the triadic model underscores the need to identify and evaluate family-focused strategies for reducing youth internalizing problems, specifically by targeting youth processes that cut across anxiety and depression. It also promotes the flexible inclusion of family members in youth interventions; parents or siblings may be involved in treatment and prevention programs based on different families' difficulties at the parent, dyad, and family levels. Beyond implications for treatment delivery approaches, our model also suggests strategies for streamlining intervention effectiveness and impact. Although the programs reviewed in this section produced positive outcomes in youths, the mechanisms through which these improvements occurred are unclear. The triadic model identifies several youth processes that might mediate effects of family-focused interventions on youth anxiety and depression symptoms. Identifying the most "active" of these mediators might support the development of targeted, efficient, transdiagnostic interventions for youth internalizing difficulties.

Target transdiagnostic, modifiable mechanisms. In recent years, the push toward developing mechanism-targeted psychological interventions has grown substantially. For example, the 2015 Strategic Plan of the National Institute of Mental
Health (NIMH, 2015) emphasizes the need for "precision medicine for mental disorders" (Cuthbert \& Insel, 2013). Specifically, for youth interventions, the NIMH (2015) stresses the need for interventions targeting specific developmental processes that underlie the development of multiple disorders. By identifying youth processes that may mediate between familial factors and youth internalizing problems, the triadic model may provide a framework for developing such interventions within a family-centered context.

The youth processes identified in our model are potentially modifiable through targeted intervention. Further, modifying each process has been shown to reduce symptoms of anxiety and depression. For instance, youths' cognitive biases toward threatening and sad stimuli may be reduced in anxious and depressed youths through cognitive bias modification, leading to improvements in internalizing difficulties (Hertel \& Mathews, 2011; Lowther \& Newman, 2014). Youths' entity theories of personality, intelligence, and social skills have become more incremental following brief interventions (Yeager et al., 2014), and these changes may prevent the development of internalizing symptoms (Miu \& Yeager, in press). A wealth of literature suggests that attachment security can be strengthened through behavioral interventions in very young children (see Bakermans-Kranenburg, van IJzendoorn, \& Juffer, 2003, for a meta-analysis), and in adolescents, through relational and cognitive behavioral strategies (Diamond et al., 2002). Individual CBT programs for youth internalizing problems, which teach cognitive restructuring and problemsolving strategies, have decreased youths' hopelessness, improved attributional styles, and increased perceived control, in turn improving depression and anxiety symptoms (Bienvenu \& Ginsburg, 2007; Collins \& Dozois, 2008; Gillham, Jaycox, Reivich, Seligman, \& Silver, 1990). Emotion awareness training and self-monitoring techniques have strengthened youths' adaptive emotional self-regulation strategies, enhanced engagement with their emotions, decreased their reliance on emotional avoidance, and improved youth internalizing trajectories (Clarke et al., 1995).

In sum, each youth process identified in the triadic model may be harnessed for developing mechanism-targeted, transdiagnostic, family-focused interventions for youth. However, at least two questions remain before this goal can be achieved. First, which youth processes best account for links between various familial factors and youth internalizing problems? Second, which of these processes most strongly mediate positive effects of family-focused intervention? Answers may inform the focus of family-based intervention strategies, potentially facilitating more powerful, precise protocols. Below, we describe research strategies for investigating these questions, based on the framework the triadic model provides.

Testing the triadic model. Several research strategies may help elucidate the direct and indirect pathways proposed by the triadic model. First, multiwave, longitudinal studies may identify youth processes that mediate relations between parent-, dyad-, and family-level factors and youth internaliz- 
ing symptoms over time. Several design features might help maximize these studies' utility. For example, it will be helpful to assess multiple familial factors at each time point in these longitudinal studies. As previously noted, facets of family process have largely been assessed as individual risk factors for youth internalizing problems; this approach has been valuable, but the triadic model highlights the value of research examining the combined, comparative, and interactive effects of these family factors on youth trajectories. The model posits familial factors at multiple levels that may be measured simultaneously in longitudinal research. Further, assessing familial factors at multiple time points would aid efforts to understand how naturally occurring changes in familial factors, for example, increases in parental psychopathology or improvements in family stability, might shape youth processes and symptoms. Second, longitudinal studies might include measures of multiple candidate mediators, or youth processes, at several consecutive time points. This would facilitate the assessment of different youth processes as concurrent mediators (e.g., through multiple mediation or structural equation modeling approaches). Researchers could then compare the relative strength of several youth processes in explaining links between family factors and youth internalizing difficulties. It will be helpful to assess different kinds of internalizing dysfunction to identify transdiagnostic versus problem-specific pathways. Third, to facilitate new research in this area, alternative data collection methods may be considered to minimize costs and resource demands associated with longitudinal studies. Schleider and Weisz (2015) found that Amazon's Mechanical Turk may be a viable tool for some kinds of longitudinal, survey-based research on family processes and youth mental health (Schleider \& Weisz, 2015). Online data collection approaches might represent a cost-effective first step in testing hypotheses linked to the triadic model for later testing via more traditional methods.

Within longitudinal studies, examining multiple models of cumulative risk may clarify the structure of relations between and among familial factors, youth processes, and youth outcomes. Specifically, it may be helpful to compare the applicability of three prominent risk models, as previously noted: independent-additive, wherein individual familial risk factors increase risk for adverse youth outcomes in a cumulative, linear pattern; interactive, wherein the association between at least one risk factor and one youth outcome variable depends on the level of at least one second factor (i.e., a stress-buffering model); and exponential models, wherein effects of various individual familial factors multiply or potentiate each other (Gerard \& Buehler, 1999; Hodges et al., 1984). These three models carry different implications for youths confronted with multiple familial adversities, and potentially for intervention. For instance, a purely additive risk model would suggest that familial risk factors each have independent direct impact, such that intervention benefit might derive from targeting any of them, or any combination, and the more familial stressors targeted in intervention the better. Conversely, if certain factors produce risk in an exponential or interactive fashion, they might represent especially promising or highimpact intervention targets, arguing for zeroing in with precision rather than addressing as many risk factors as possible. Longitudinal path analysis and structural equation modeling techniques would be well suited to comparing risk models in large youth samples in ways that would carry intervention implications.

Second, experimental research will be needed to test whether youth processes identified in the triadic model can be altered by manipulating family factors at the parent, dyad, or family level. For instance, such studies might assess whether systematic changes in parental praise might affect youths' implicit theories; whether increasing stability in family routines might strengthen youths' attachment or perceived control; or whether altering parents' modeling styles in specific ways shapes youth withdrawal behavior or threat bias. In such studies, it will be helpful to test for spillover effects to determine whether improvements in one familial factor (e.g., parental autonomy-granting behaviors) might generalize to other family domains (e.g., positive parental modeling or family functioning) and, in turn, additional youth processes. This kind of research will help determine which youth processes are most malleable and how to most effectively and efficiently alter them. Thus, experimental studies may identify targeted approaches to reducing or preventing maladaptive youth processes, and, in turn, internalizing problems, through family-based interventions.

Third, for those family factors that are amenable to change, it will be important to test whether such change does influence risk or severity of internalizing problems. Triadic model pathways may be tested through efficacy and effectiveness trials for family-, dyad-, or parent-based interventions targeting youth internalizing problems. For instance, trials might include pre-, mid-, and posttreatment assessments of youth processes such as cognitive style, control-related beliefs, cognitive biases, or implicit theories. Including these assessments will allow researchers to examine whether a family-focused intervention strategy directly affects transdiagnostic youth processes, as well as whether changes in these processes mediate reductions in symptoms over time.

For any study testing the triadic model, sample selection will be an important consideration. In order to maximize the potential utility of results, and in line with recommendations from the NIMH's Research Domain Criteria Project (Cuthbert \& Insel, 2013), it may be helpful to recruit youths with a wide range of baseline internalizing problems. The triadic model is intended to guide efforts toward treatment and prevention; thus, including youths with clinically elevated, subclinical, and normative levels of internalizing dysfunction will help establish the model's applicability to both domains. A second strategy for sample selection, complementary to the first, might be to target families with significant difficulties in one or more parent-, dyad-, or family-level domains. For example, in a study examining whether reducing parental psychological control and increasing autonomy-granting behaviors predicts improved attributional style 
in offspring, researchers might focus on parents exhibiting maladaptive levels of psychologically controlling behavior. This would allow researchers to test the strength of theorized mechanisms in families at greatest risk. Third, because child age and gender can affect relations among familial factors, youth processes, and internalizing problems, researchers should consider the role of these variables prior to selecting samples. For example, if investigators plan to explore how cognitive styles and control-related beliefs affect treatment response, they might consider focusing on adolescents, for whom these beliefs may be better developed and more likely to shape internalizing distress (Nowicki \& Strickland, 1973). They should also aim to recruit a sufficient number of participants to test child gender as an outcome moderator, given the potentially greater effect of cognitive styles on internalizing problems in girls than in boys (Hamilton et al., 2015). Such considerations may improve the specificity and clinical utility of eventual findings.

Fourth, when testing the strength of novel interventions, it will be critical for researchers to select strong control conditions. Specifically, this would involve comparing the effectiveness of novel, family-focused programs, or existing programs with added family modules, to that of child-focused, empirically supported interventions. A major goal of the triadic model is to guide research toward increasing the proportion of youths who benefit from interventions for internalizing problems by improving upon current interventions that are known to be effective. Relying on no-treatment, attention-only, or wait-list control groups might generate artificially large intervention effects but would not provide a test of whether this goal had been attained. The point is that researchers should investigate whether family-focused programs drawn from the triadic model can actually outperform or enhance existing gold-standard protocols.

\section{Outstanding questions, considerations, and conclusions}

In applying the triadic model to research on the development, prevention, and treatment of youth internalizing problems, some caveats and outstanding questions warrant mention. First, the present paper focuses on development, prevention, and treatment of youth internalizing problems. Thus, the directional pathway from familial factors to youth problems is emphasized throughout. However, it is important to recognize that the relations among parent-, dyad-, and family-level factors, as well as youth processes discussed, are multidirectional: each factor is likely to relate bidirectionally with the others. Youth internalizing problems may reinforce specific family factors at the parent, family, and dyad levels (e.g., through family- and parentinitiated accommodation behaviors in response to youth anxiety and depression). As a complement to our present focus, the triadic model can guide empirical assessments of these multidirectional pathways. For instance, the youth processes identified might also mediate relations between youth problems and familial factors over time.

Second, like all empirical findings in the area of youth psychopathology, the pathways outlined in the triadic model can- not be applied directly to all families. Different children have widely varying personalities, preferences, and predispositions, and this diversity can mean that the very same family factors and dyadic patterns can have different effects from one child to the next. For example, parental psychopathology will not always lead to insecure youth attachment, nor will specific parental praise patterns always promote improvements in children's perceived control. The triadic model suggests statistically probable pathways, and can inform intervention strategies that are most likely to be effective. However, some strategies may require fitting a particular parenting approach to a given child characteristics, such as age, gender, and temperament. This caveat underscores the importance of the flexible adaptation of family-based treatment and prevention approaches, based on each family's strengths, difficulties, and goals. Assessment strategies like those we outlined above will be needed to guide the personalizing process that individual youth and family diversity will necessitate.

Youth comorbid externalizing problems are also important to consider, as they might necessitate family-specific fitting of certain intervention strategies. Many children with internalizing difficulties also have behavior and conduct problems (Ollendick, Jarret, Griss-Tacquechel, Hovey, \& Wolff, 2008), which can relate to familial factors in different ways than those reviewed in this paper (Bailey, Hill, Oesterle, \& Hawkins, 2006; Beyers, Bates, Pettit, \& Dodge, 2003). Thus, it will be interesting to explore, in future research, how the present model might apply to youths with externalizing as well as internalizing difficulties, and what sorts of intervention modifications may be most useful for their families. Additional research, as described in the preceding section, may provide clarity on this point.

Third and finally, the triadic model addresses the development of internalizing problems, broadly defined. Each family factor presented has shown links to both anxiety and depressive symptoms in youths; however, the degree of comorbidity between these symptoms and disorders is far from 100\% (Weersing et al., 2012). Some youths are primarily anxious, with few or no depressive symptoms, and others are clinically depressed but show few signs of anxiety. Future research based on the triadic model should consider how the same familial factors may lead to such divergent outcomes for youths. For instance, youths' differing genetic endowments (Hettema, 2008), neural circuity (Phillips, Drevets, Rauch, \& Lane, 2003), or temperament (Caspi, Moffitt, Newman, \& Silva, 1996), might lead them to react to familial stress in ways consistent with either anxiety or depression. In addition, youths may develop anxiety or depression depending on the timing of the stress they experience. In genetically, neurobiologically, or cognitively vulnerable children, stressors that occur in childhood may produce anxiety, whereas those occurring during adolescence may lead to depression. The developmental progression from anxiety to depression may reflect a "readiness" (Kovacs \& Devlin, 1998, p. 54) to show certain physiological aspects of anxiety (e.g., agitation or hyperarousal) earlier in development, and certain other physio- 
logical (e.g., vegetative symptoms) and cognitive (e.g., rumination) aspects of depression later. Alternatively, certain kinds of familial stressors may impinge primarily on different youth processes, and in turn different kinds of internalizing problems. For example, stressors influencing threat bias may be more strongly linked to youth anxiety, whereas those that exacerbate hopelessness and negative attributional style may be more likely to lead to depression. Exploring these possibilities may extend the impact of the empirical framework for youth internalizing problems provided here.

\section{References}

Abela, J. R. Z. (2001). The hopelessness theory of depression: A test of the diathesis-stress and causal mediation components in third and seventh grade children. Journal of Abnormal Child Psychology, 29, 241-254.

Abela, J. R. Z., Hankin, B. L., Haigh, E. A. P., Adams, P., Vinokuroff, T., \& Trayhern, L. (2005). Interpersonal vulnerability to depression in high-risk children: The role of insecure attachment and reassurance seeking. Journal of Clinical Child and Adolescent Psychology, 34, 182-192.

Abela, J. R. Z., \& Sarin, S. (2002). Cognitive vulnerability to hopelessness depression: A chain is only as strong as its weakest link. Cognitive Therapy and Research, 26, 811-829.

Abrams, S. M., Field, T., Scafidi, F., \& Prodromidis, M. (1995). Newborns of depressed mothers. Infant Mental Health Journal, 16, 233-239.

Abramson, L., Seligman, M., \& Teasdale, J. (1978). Learned helplessness in humans: Critique and reformulation. Journal of Abnormal Psychology, $57,49-74$.

Ainsworth, M. D. S., Blehar, M. C., Waters, E., \& Wall, S. (1978). Patterns of attachment: A psychological study of the strange situation. Hillsdale, NJ: Erlbaum.

Alessandri, S. M., \& Lewis, M. (1993). Parental evaluation and its relation to shame and pride in young children. Sex Roles, 29, 335-343.

Alloy, L. B., Abramson, L. Y., Whitehouse, W. G., Hogan, M. E., Panzarella, C., \& Rose, D. T. (2006). Prospective incidence of first onsets and recurrences of depression in individuals at high and low cognitive risk for depression. Journal of Abnormal Psychology, 115, 145-156.

Alloy, L. B., Kelly, K. A., Mineka, S., \& Clements, C. M. (1990). Comorbidity of anxiety and depressive disorders: A helplessness-hopelessness perspective. In J. D. Maser \& C. R. Cloninger (Eds.), Comorbidity of mood and anxiety disorders (pp. 499-503). Washington, DC: American Psychiatric Press.

Amato, P. R. (2001). Children of divorce in the 1990s: An update of the Amato and Keith (1991) meta-analysis. Journal of Family Psychology, $15,355-370$.

Anderson, C. A., \& Hammen, C. L. (1993). Psychosocial outcomes of children of unipolar depressed, bipolar, medically ill, and normal women: A longitudinal study. Journal of Consulting \& Clinical Psychology, 61, $448-454$.

Anderson, J. C., Williams, S. M., McGee, R., \& Silva, P. A. (1987). DSM-III disorders in preadolescent children: Prevalence in a large sample from the general population. Archives of General Psychiatry, 44, 69-76.

Andsager, J. L., Bemker, V., Choi, H.-L., \& Torwell, V. (2006). Perceived similarity of exemplar traits and behavior. Communication Research, 33, 3-18.

Angold, A., Costello, E. J., \& Erkanli, A (1999). Comorbidity. Journal of Child Psychology and Psychiatry, 40, 57-87.

Angold, A., \& Rutter, M. (1992). Effects of age and pubertal status on depression in a large clinical sample. Development and Psychopathology, 4, $5-28$.

Appleyard, K., Egeland, B., van Dulmen, M., \& Sroufe, L. A. (2005). When more is not better: The role of cumulative risk in child behavior outcomes. Journal of Child Psychology and Psychiatry, 46, 235-245.

Asarnow, J. R., Scott, C. V., \& Mintz, J. (2002). A combined cognitive-behavioral family education intervention for depression in children: A treatment development study. Cognitive Therapy and Research, 26, 221-229.

Atzaba-Poria, N., \& Pike, A. (2008). Correlates of parental differential treatment: Parental and contextual factors during middle childhood. Child Development, 79, 217-232.
In summary, this paper introduced the triadic model of family process: a theoretical framework for exploring relations between family processes and youth internalizing problems. We hope that this model may facilitate investigations of how different components of family process relate to each other and to youth internalizing problems. Through longitudinal, experimental, and intervention evaluation research, we hope the triadic model will ultimately help scaffold the development of mechanism-targeted, family-based interventions for youth internalizing problems.

Avenevoli, S., \& Merikangas, K. R. (2006). Implications of high-risk family studies for prevention of depression. American Journal of Preventive Medicine, 31, 126-235.

Axinn, W. G., Young-DeMarco, L., \& Ro, M. C. (2011). Gender double standards in parenting attitudes. Social Science Research, 40, 417-432.

Bailey, J. A., Hill, K. G., Oesterle, S., \& Hawkins, J. D. (2006). Linking substance use and problem behavior across three generations. Journal of $A b-$ normal Child Psychology, 34, 273-292.

Bakermans-Kranenburg, M. J., van IJzendoorn, M. H., \& Juffer, F. (2003). Less is more: Meta-analyses of sensitivity and attachment interventions in early childhood. Psychological Bulletin, 129, 195-215.

Baldwin, A. L. (1948). Socialization and the parent-child relationship. Child Development, 19, 127-136.

Ballash, N., Leyfer, O., Buckley, A. F., \& Woodruff-Borden, J. (2006). Parental control in the etiology of anxiety. Clinical Child and Family Psychology Review, 9, 113-133.

Bank, L., Burraston, B., \& Snyder, J. (2004). Sibling conflict and ineffective parenting as predictors of adolescent boys' antisocial behavior and peer difficulties: Additive and interactional effects. Journal of Research on Adolescence, 14, 99-125.

Barber, B. K. (1996). Parental psychological control: Revisiting a neglected construct. Child Development, 67, 3296-3319.

Barlow, D. H., Allen, L. B., \& Choate, M. L. (2004). Toward a unified treatment for emotional disorders. Behavior Therapy, 35, 205-230.

Barrett, P. M., Dadds, M. R., Rapee, R., \& Ryan, S. (1996). Family enhancement of cognitive style in anxious and aggressive children. Journal of Abnormal Child Psychology, 24, 187-203.

Baumeister, R. F., Hutton, D. G., \& Cairns, K. J. (1990). Negative effects of praise on skilled performance. Basic and Applied Social Psychology, 11, 131-148.

Baumrind, D. (1967). Child care practices anteceding three patterns of preschool behavior. Genetic Psychology Monographs, 75, 43-88.

Baumrind, D. (1971). Current patterns of parental authority. Developmental Psychology Monographs, 4, 1-103.

Baumrind, D. (1978). Parental disciplinary patterns and social competence in children. Youth Socialization, 9, 239-276.

Baumrind, D. (1989). Rearing competent children. In W. Damon (Ed.), Child development today and tomorrow (pp. 349-378). San Francisco, CA: Jossey-Bass.

Becker, W. C. (1964). Consequences of different kinds of parental discipline. In M. L. Hoffman \& L. W. Hoffman (Eds.), Review of child development research (Vol. 1, pp. 169-208). New York: Russell Sage Foundation.

Beesdo, K., Knappe, S., \& Pine, D. S. (2009). Anxiety and anxiety disorders in children and adolescents: Developmental issues and implications for DSM-V. Psychiatric Clinics of North America, 32, 483-524.

Beidel, D. C. \& Turner, S. M. (1997). At risk for anxiety: I. Psychopathology in the offspring of anxious parents. Journal of the American Academy of Child \& Adolescent Psychiatry, 36, 918-924.

Bell, R. Q. (1968). A reinterpretation of the direction of effects in studies of socialization. Psychological Review, 75, 81-95.

Bell, R. Q. (1979). Parent, child, and reciprocal influences. American Psychologist, 34, 821-826.

Bell-Dolan, D., Last, C. G., \& Strauss, C. C. (1990). Symptoms of anxiety disorders in normal children. Journal of the American Academy of Child \& Adolescent Psychiatry, 29, 759-765.

Bernstein, G. A., Warren, S. L., Massie, E. D., \& Thuras, P. D. (1999). Family dimensions in anxious-depressed school refusers. Journal of Anxiety Disorders, 13, 513-528. 
Beyers, J. M., Bates, J. E., Pettit, G. S., \& Dodge, K. A. (2003). Neighborhood structure, parenting processes, and the development of youths' externalizing behaviors: A multilevel analysis. American Journal of Community Psychology, 31, 35-53.

Bienvenu, O. J., \& Ginsburg, G. S. (2007). Prevention of anxiety disorders. International Review of Psychiatry, 19, 647-654.

Birmaher, B., Brent, D., \& AACAP Work Group on Quality Issues. (2007). Practice parameter for the assessment and treatment of children and adolescents with depressive disorders. Journal of the American Academy of Child \& Adolescent Psychiatry, 46, 1503-1526.

Blackwell, L. S., Trzesniewski, K. H., \& Dweck, C. S. (2007). Implicit theories of intelligence predict achievement across an adolescent transition: A longitudinal study and an intervention. Child Development, 78, 246263.

Blossom, J. B., Ginsburg, G. S., Birmaher, B., Walkup, J. T., Kendall, P. C., Keeton, C. P., et al. (2013). Parental and family factors as predictors of threat bias in anxious youth. Cognitive Therapy and Research. Advance online publication.

Bögels, S. M., \& Brechman-Toussaint, M. L. (2006). Parenting issues in child anxiety: Attachment, family functioning, parental rearing, and beliefs. Clinical Psychology Review, 26, 834-856.

Bowlby, J. (1973). Attachment and loss: Vol. 2. Separation. New York: Basic Books.

Bowlby, J. (1980). Attachment and loss: Vol. 3. Loss: Sadness and depression. New York: Basic Books.

Boyle, M. H., Jenkins, J. M., Georgiades, K., Cairney, J., Duku, E., \& Racine, Y. (2004). Differential-maternal parenting behavior: Estimating within- and between-family effects on children. Child Development, 75, 1457-1476.

Breinholst, S., Esbjørn, B. H., Reinholdt-Dunne, M. L., \& Stallard, P. (2012). CBT for the treatment of child anxiety disorders: A review of why parental involvement has not enhanced outcomes. Journal of Anxiety Disorders, 26, 416-424.

Brenning, K., Soenens, B., Braet, C., \& Bal, S. (2012). The role of parenting and mother-adolescent attachment in the intergenerational similarity of internalizing symptoms. Journal of Youth and Adolescence, 41, 802816.

Brock, R. L., \& Kochanska, G. (2015). Interparental conflict, children's security with parents, and long-term risk of internalizing problems: A longitudinal study from age 2 to 10. Development and Psychopathology. Advance online publication.

Brody, G. H. (2004). Siblings' direct and indirect contributions to child development. Current Directions in Psychological Science, 13, 124-126.

Brooks-Gunn, J., \& Duncan, G. J. (1997). The effects of poverty on children. Future of Children, 7, 55-71.

Brummelman, E., \& Thomaes, S. (2011). [Parents' beliefs about praise]. Unpublished raw data.

Brummelman, E., Thomaes, S., Orobio de Castro, B., Overbeek, G., \& Bushman, B. J. (2014). "That's not just beautiful-That's incredibly beautiful!": The adverse impact of inflated praise on children with low self-esteem. Psychological Science, 25, 728-735.

Buist, K. L., Deković, M., \& Prinzie, P. (2013). Sibling relationship quality and psychopathology of children and adolescents: A meta-analysis. Clinical Psychology Review, 33, 97-106.

Burnette, J. L., O’Boyle, E. H., Vanepps, E. M., Pollack, J. M., \& Finkel, E. J. (2013). Mind-sets matter: A meta-analytic review of implicit theories and self-regulation. Psychological Bulletin, 139, 655-701.

Burstein, M., \& Ginsburg, G. S. (2010). The effect of parental modeling of anxious behaviors and cognitions in school-aged children: An experimental pilot study. Behaviour Research and Therapy, 48, 506-515.

Campione-Barr, N., Greer, K. B., \& Kruse, A. (2013). Differential associations between domains of sibling conflict and adolescent emotional adjustment. Child Development, 84, 938-954.

Campo, J. V., Bridge, J., Ehmann, M., Altman, S., Lucas, A., Birmaher, B., et al. (2004). Recurrent abdominal pain, anxiety, and depression in primary care. Pediatrics, $113,817-824$.

Cannon, M. F., \& Weems, C. F. (2010). Cognitive biases in childhood anxiety disorders: Do interpretive and judgment biases distinguish anxious youth from their non-anxious peers? Journal of Anxiety Disorders, 24, 751-758.

Carpenter, A. L., Puliafico, A. C., Kurtz, S. M., Pincus, D. B., \& Comer, J. S. (2014). Extending parent-child interaction therapy for early childhood internalizing problems: New advances for an overlooked population. Clinical Child and Family Psychology Review, 17, 340-356.
Carter, M. J. (2014). Gender socialization and identity theory. Social Sciences, 3, 242-263.

Carver, C. S., Johnson, S. L., \& Joormann, J. (2008). Serotonergic function, two-mode models of self-regulation, and vulnerability to depression: What depression has in common with impulsive aggression. Psychological Bulletin, 134, 912.

Caspi, A., Moffitt, T. E., Newman, D. L., \& Silva, P. A. (1996). Behavioral observations at age 3 years predict adult psychiatric disorders: Longitudinal evidence from a birth cohort. Archives of General Psychiatry, 53, 1033-1039.

Chorpita, B. F. (2001). Control and the development of negative emotion. In M. W. Vasey \& M. R. Dadds (Eds.), The developmental psychopathology of anxiety (pp. 112-142). New York: Oxford University Press.

Chorpita, B. F., Albano, A. M., \& Barlow, D. H. (1996). Cognitive processing in children: Relation to anxiety and family influences. Journal of Clinical Child Psychology, 25, 170-176.

Chorpita, B. F., \& Barlow, D. H. (1998). The development of anxiety: The role of control in the early environment. Psychological Bulletin, 124, 3.

Chorpita, B. F., Brown, T. A., \& Barlow, D. H. (1998). Perceived control as a mediator of family environment in etiological models of childhood anxiety. Behavior Therapy, 29, 457-476.

Cimpian, A., Arce, H., Markman, E., \& Dweck, C. (2007). Subtle linguistic cues affect children's motivation. Psychological Science, 18, 314-316.

Clark, K. E., \& Ladd, G. W. (2000). Connectedness and autonomy support in parent-child relationships: Links to children's socioemotional orientation and peer relationships. Developmental Psychology, 36, 485-498.

Clark, L. A., \& Watson, D. (1991). Tripartite model of anxiety and depression: Psychometric evidence and taxonomic implications. Journal of $A b-$ normal Psychology, 100, 316-336.

Clarke, G. N., \& DeBar, L. (2010). Group cognitive-behavioral treatment for adolescent depression. In J. R. Weisz \& A. E. Kazdin (Eds.), Evidencebased psychotherapies for children and adolescents (2nd ed., pp. 110125). New York: Guilford Press.

Clarke, G. N., Hawkins, W., Murphy, M., Sheeber, L. B., Lewinsohn, P. M., \& Seeley, J. R. (1995). Targeted prevention of unipolar depressive disorder in an at-risk sample of high school adolescents: A randomized trial of a group cognitive intervention. Journal of the American Academy of Child \& Adolescent Psychiatry, 34, 312-321.

Cole, D. A., Truglio, R., \& Peeke, L. (1997). Relation between symptoms of anxiety and depression in children: A multitrait-multimethod-multigroup assessment. Journal of Consulting and Clinical Psychology, 65, 110.

Collins, K. A., \& Dozois, D. J. (2008). What are the active ingredients in preventative interventions for depression? Clinical Psychology: Science and Practice, 15, 313-330.

Connell, A. M., \& Goodman, S. H. (2002). The association between psychopathology in fathers versus mothers and children's internalizing and externalizing behavior problems: A meta-analysis. Psychological Bulletin, $128,746$.

Connell, J. P. (1985). A new multidimensional measure of children's perceptions of control. Child Development, 56, 1018-1041.

Corpus, J. H., \& Lepper, M. R. (2007). The effects of person versus performance praise on children's motivation: Gender and age as moderating factors. Educational Psychology, 27, 487-508.

Cortes, R. C., Fleming, C. B., Catalano, R. F., \& Brown, E. C. (2006). Gender differences in the association between maternal depressed mood and child depressive phenomena from Grade 3 through Grade 10. Journal of Youth and Adolescence, 35, 810-821.

Cox, M. J., Paley, B., Payne, C. C., \& Burchinal, M. (1999). The transition to parenthood: Marital conflict and withdrawal and parent-infant interactions. In M. J. Cox \& J. Brooks-Gunn (Eds.), Conflict and cohesion in families: Causes and consequences (pp. 87-104). Mahwah, NJ: Erlbuam.

Crawford, T. N., Cohen, P., Midlarsky, E., \& Brook, J. S. (2001). Internalizing symptoms in adolescents: Gender differences in vulnerability to parental distress and discord. Journal of Research on Adolescence, 11 95-118.

Cui, L., Morris, A. S., Criss, M. M., Houltberg, B. J., \& Silk, J. S. (2014). Parental psychological control and adolescent adjustment: The role of adolescent emotion regulation. Parenting, 14, 47-67.

Cummings, C. M., Caporino, N. E., \& Kendall, P. C. (2014). Comorbidity of anxiety and depression in children and adolescents: 20 years after. Psychological Bulletin, 140, 816-845.

Cummings, E. M. (1994). Marital conflict and children's functioning. Social Development, 3, 16-36. 
Cummings, E. M., \& Cicchetti, D. (1990). Toward a transactional model of relations between attachment and depression. In M. T. Greenberg, D. Cicchetti, \& E. M. Cummings (Eds.), Attachment in the preschool years: Theory, research and intervention (pp. 339-372). Chicago: University of Chicago Press.

Cummings, E. M., Goeke-Morey, M. C., \& Papp, L. M. (2003). Children's responses to everyday marital conflict tactics in the home. Child Development, 74, 1918-1929.

Cuthbert, B. N., \& Insel, T. R. (2013). Toward the future of psychiatric diagnosis: The seven pillars of RDoC. BMC Medicine, 11, 1-8.

Dadds, M. R., Holland, D. E., Laurens, K. R., Mullins, M., Barrett, P. M., \& Spence, S. H. (1999). Early intervention and prevention of anxiety disorders in children: Results at 2-year follow-up. Journal of Consulting and Clinical Psychology, 67, 145.

Dalgleish, T., Taghavi, R., Neshat-Doost, H., Moradi, A., Canterbury, R., \& Yule, W. (2003). Patterns of processing bias for emotional information across clinical disorders: A comparison of attention, memory, and prospective cognition in children and adolescents with depression, generalized anxiety, and posttraumatic stress disorder. Journal of Clinical Child and Adolescent Psychology, 32, 10-21.

Davies, P. T., \& Cummings, E. M. (1994). Marital conflict and child adjustment: An emotional security hypothesis. Psychological Bulletin, 116, 387-411.

Dawson, D. A. (1991). Family structure and children's health and well-being: Data from the 1988 National Health Interview Survey on Child Health. Journal of Marriage and the Family, 53, 573-584.

Dawson, G., Ashman, S. B., Panagiotides, H., Hessl, D., Self, J., Yamada, E., et al. (2003). Preschool outcomes of children of depressed mothers: Role of maternal behavior, contextual risk, and children's brain activity. Child Development, 74, 1158-1175.

Deal, J. E. (1996). Marital conflict and differential treatment of siblings. Family Process, 35, 333-346.

De Man, A. F. (1986). Parental control in child rearing and trait anxiety in young adults. Psychological Reports, 59, 477-478.

de Rosnay, M., Cooper, P. J., Tsigaras, N., \& Murray, L. (2006). Transmission of social anxiety from mother to infant: An experimental study using a social referencing paradigm. Behaviour Research and Therapy, 44, $1165-1175$.

Diamond, G. S., Reis, B. F., Diamond, G. M., Siqueland, L., \& Isaacs, L. (2002). Attachment-based family therapy for depressed adolescents: A treatment development study. Journal of the American Academy of Child \& Adolescent Psychiatry, 41, 1190-1196.

Diamond, G. S., Wintersteen, M. B., Brown, G. K., Diamond, G. M., Gallop, R., Shelef, K., et al. (2010). Attachment-based family therapy for adolescents with suicidal ideation: A randomized controlled trial. Journal of the American Academy of Child \& Adolescent Psychiatry, 49, 122131.

Diener, M., Mangelsdorf, S., Fosnot, K., \& Kienstra, M. (1997). Effects of maternal involvement on toddlers' emotion regulation strategies. Paper presented at the biennial meeting of the Society for Research in Child Development, Washington, DC.

Dobkin, R. D., Allen, L. A., Alloy, L. B., Menza, M., Gara, M. A., \& Panzarella, C. (2007). Adaptive inferential feedback partner training for depression: A pilot study. Cognitive and Behavioral Practice, 14, 350-363.

Dodge, K. A., Pettit, G. S., \& Bates, J. E. (1994). Socialization and mediators of the relation between socioeconomic status and child conduct problems. Child Development, 65, 649-665.

Drake, K. L., \& Ginsburg, G. S. (2012). Family factors in the development, treatment, and prevention of childhood anxiety disorders. Clinical Child and Family Psychology Review, 15, 144-162.

Dumas, J., LaFreniere, E., \& Serketich, W. (1995). "Balance of power": Transactional analysis of control in mother-child dyads involving socially competent, aggressive, and anxious children. Journal of Abnormal Psychology, 104, 104-113.

Du Rocher Schudlich, T. D., \& Cummings, E. M. (2003). Parental dysphoria and children's internalizing symptoms: Marital conflict styles as mediators of risk. Child Development, 74, 1663-1681.

Dweck, C. S. (1975). The role of expectations and attributions in the alleviation of learned helplessness. Journal of Personality and Social Psychology, 31, 674-685.

Dweck, C. S. (1986). Motivational processes affecting learning. American Psychologist, 41, 1040-1048.

Dweck, C. S. (1999). Self-theories: Their role in motivation, personality, and development. New York: Psychology Press.
Dweck, C. S., Davidson, W., Nelson, S., \& Enna, B. (1978) Sex differences in learned helplessness: II. The contingencies of evaluative feedback in the classroom; and III. An experimental analysis. Developmental Psychology, 14, 268-276.

East, P. L., \& Rook, K. S. (1992). Compensatory patterns of support among children's peer relationships: A test using school friends, nonschool friends, and siblings. Developmental Psychology, 28, 163-172.

Eckshtain, D., Kuppens, S., \& Weisz, J. R. (in press). Amelioration of child depression through behavioral parent training: A preliminary study. Journal of Clinical Child \& Adolescent Psychology.

Ehrenreich-May, J., \& Bilek, E. L. (2012). The development of a transdiagnostic, cognitive behavioral group intervention for childhood anxiety disorders and co-occurring depression symptoms. Cognitive and Behavioral Practice, 19, 41-55.

Ehrenreich-May, J., \& Chu, B. C. (2013). Overview of transdiagnostic mechanisms and treatments for youth psychopathology. In J. Ehrenreich-May \& B. C. Chu (Eds.), Transdiagnostic treatments for children and adolescents: Principles and practices (pp. 3-14). New York: Guilford Press.

Eisen, A. R., Brien, L. K., Bowers, J., \& Strudler, A. (2001). Separation anxiety disorder. In C. A. Essau \& F. Petermann (Eds.), Anxiety disorders in children and adolescents: Epidemiology, risk factors, and treatment. London: Harwood Academic.

Eisenberg, M. E., Olson, R. E., Neumark-Sztainer, D., Story, M., \& Bearinger, L. H. (2004). Correlations between family meals and psychosocial well-being among adolescents. Archives of Pediatrics \& Adolescent Medicine, 158, 792-796.

Eisenberg, N., Spinrad, T. L., \& Eggum, N. D. (2010). Emotion-related selfregulation and its relation to children's maladjustment. Annual Review of Clinical Psychology, 6, 495

Eldar, S., Ricon, T., \& Bar-Haim, Y. (2008). Plasticity in attention: Implications for stress response in children. Behaviour Research and Therapy, $46,450-461$

Erdley, C. A., Cain, K. M., Loomis, C. C., Dumas-Hines, F., \& Dweck, C. S. (1997). Relations among children's social goals, implicit personality theories, and responses to social failure. Developmental Psychology, 33, 263-272.

Erel, O., \& Burman, B. (1995). Interrelatedness of marital relations and parent-child relations: A meta-analytic review. Psychological Bulletin, 118, 108.

Evans, G. W. (2003). A multimethodological analysis of cumulative risk and allostatic load among rural children. Developmental Psychology, 39, 924

Eyberg, S. M., \& Funderburk, B. (2011). Parent-child interaction therapy protocol. Gainesville, FL: PCIT International.

Eysenck, H. J. (1967). The biological basis of personality (Vol. 689). Piscataway, NJ: Transaction.

Eysenck, H. J., \& Eysenck, S. B. G. (1975). Manual of the Eysenck Personality Questionnaire. London: Hodder and Stoughton.

Feinberg, M. E., Neiderhiser, J. M., Simmens, S., Reiss, D., \& Hetherington, E. M. (2000). Sibling comparison of differential parental treatment in adolescence: Gender, self-esteem, and emotionality as mediators of the parenting-adjustment association. Child Development, 71, 16111628.

Feinberg, M. E., Solmeyer, A. R., Hostetler, M. L., Sakuma, K. L., Jones, D., \& McHale, S. M. (2013). Siblings are special: Initial test of a new approach for preventing youth behavior problems. Journal of Adolescent Health, 53, 166-173.

Fergusson, D. M., \& Horwood, L. J. (1998). Exposure to interparental violence in childhood and psychosocial adjustment in young adulthood. Child Abuse \& Neglect, 22, 339-357.

Festinger, L. (1954). A theory of social comparison processes. Human Relations, 7, 117-140.

Fiese, B. H. (1992). Dimensions of family rituals across two generations: Relation to adolescent identity. Family Process, 31, 151-162.

Fincham, F. D., \& Cain, K. M. (1986). Learned helplessness in humans: A developmental analysis. Developmental Review, 6, 301-333.

Fisak, B., Jr., \& Grills-Taquechel, A. E. (2007). Parental modeling, reinforcement, and information transfer: Risk factors in the development of child anxiety. Clinical Child and Family Psychology Review, 10, 213231.

Freud, S. (1933). New introductory lectures in psychoanalysis. New York: Norton.

Fuligni, A., \& Masten, C. L. (2010). Daily family interactions among young adults in the United States from Latin American, Filipino, East Asian, and 
European backgrounds. International Journal of Behavioral Development, 34, 491-499.

Gabriel, S., \& Gardner, W. L. (1999). Are there "his" and "hers" types of interdependence? The implications of gender differences in collective versus relational interdependence for affect, behavior, and cognition. Journal of Personality and Social Psychology, 77, 642.

Gaensbauer, T. J., Harmon, R. J., Cytryn, L., \& McKnew, D. H. (1984). Social and affective development in infants with a manic-depressive parent. American Journal of Psychiatry, 141, 223-229.

Garber, J. (2006). Depression in children and adolescents: Linking risk research and prevention. American Journal of Preventive Medicine, 31, $104-125$.

Garber, J., \& Flynn, C. A. (2001). Predictors of depressive cognitions in young adolescents. Cognitive Therapy and Research, 25, 353-376.

Garber, J., \& Weersing, V. R. (2010). Comorbidity of anxiety and depression in youth: Implications for treatment and prevention. Clinical Psychology: Science and Practice, 17, 293-306.

Garnefski, N., Kraaij, V., \& van Etten, M. (2005). Specificity of relations between adolescents' cognitive emotion regulation strategies and internalizing and externalizing psychopathology. Journal of Adolescence, 28, 619-631.

Gass, K., Jenkins, J., \& Dunn, J. (2007). Are sibling relationships protective? A longitudinal study. Journal of Child Psychology and Psychiatry, and Allied Disciplines, 48, 167-175.

Ge, X., Lorenz, F. O., Conger, R. D., Elder, G. H., \& Simons, R. L. (1994). Trajectories of stressful life events and depressive symptoms during adolescence. Developmental Psychology, 30, 467-483.

Gelfand, D., \& Teti, D. (1990). The effects of maternal depression on children. Clinical Psychology Review, 10, 329-353.

Gerard, J. M., \& Buehler, C. (1999). Multiple risk factors in the family environment and youth problem behaviors. Journal of Marriage and the Family, 61, 343-361.

Gerull, F. C., \& Rapee, R. M. (2002). Mother knows best: Effects of maternal modelling on the acquisition of fear and avoidance behaviour in toddlers. Behaviour Research and Therapy, 40, 279-287.

Gillham, J. E., Jaycox, L. H., Reivich, K. J., Seligman, M. E. P., \& Silver, T. (1990). The Penn Optimism Program. Unpublished manuscript, University of Pennsylvania.

Ginsburg, G. S., Riddle, M., \& Davies, M. (2006). Somatic symptoms in children and adolescents with anxiety disorders. Journal of the American Academy of Child \& Adolescent Psychiatry, 45, 1179-1187.

Gladstone, T. R., Kaslow, N. J., Seeley, J. R., \& Lewinsohn, P. M. (1997). Sex differences, attributional style, and depressive symptoms among adolescents. Journal of Abnormal Child Psychology, 25, 297-306.

Goodman, S. H. (1992). Understanding the effects of depressed mothers on their children. Progress in Experimental Personal Psychopathology, 15, 47-109.

Goodman, S. H. (2007). Depression in mothers. In S. Nolen-Hoeksema, T. D. Cannon, \& T. Widiger (Eds.), Annual review of clinical psychology (Vol. 3, pp. 107-135). Palo Alto, CA: Annual Reviews.

Goodman, S. H., \& Gotlib, I. H. (1999). Risk for psychopathology in the children of depressed mothers: A developmental model for understanding mechanisms of transmission. Psychological Review, 106, 458-490.

Goodman, S. H., Rouse, M. H., Connell, A. M., Broth, M. R., Hall, C. M., \& Heyward, D. (2011). Maternal depression and child psychopathology: A meta-analytic review. Clinical Child and Family Psychology Review, 14, $1-27$.

Gotlib, I. H., Joormann, J., \& Foland-Ross, L. C. (2014). Understanding familial risk for depression: A 25 -year perspective. Perspectives on Psychological Science, 9, 94-108.

Grolnick, W. S., \& Farkas, M. (2002). Parenting and the development of children's self-regulation. Handbook of parenting (Vol. 5, pp. 89-110). Mahwah, NJ: Erlbaum.

Guidubaldi, J., Cleminshaw, H. K., Perry, J. D., Nastasi, B. K., \& Lightel, J. (1986). The role of selected family environment factors in children's post-divorce adjustment. Family Relations, 35, 141-151.

Gunderson, E., Gripshover, S. J., Romero, C., Dweck, C. S., Goldin-Meadow, S., \& Levine, S. C. (2013). Parent praise to 1- to 3-year-olds predicts children's motivational frameworks 5 years later. Child Development, 84 , 1526-1541.

Hamilton, J. L., Stange, J. P., Abramson, L. Y., \& Alloy, L. B. (2015). Stress and the development of cognitive vulnerabilities to depression explain sex differences in depressive symptoms during adolescence. Clinical Psychological Science, 3, 702-714.
Hamilton, M. A., \& Hunter, J. E. (1998). The effect of language intensity on receiver evaluations of message, source, and topic. In M. Allen \& R. W. Preiss (Eds.), Persuasion: Advances through meta-analysis (pp. 99138). Cresskill, NJ: Hampton Press.

Hammen, C. (1992). Life events and depression: The plot thickens. American Journal of Community Psychology, 20, 179-193.

Hammen, C. (2009). Adolescent depression: stressful interpersonal contexts and risk for recurrence. Current Directions in Psychological Science, 18, 200-204.

Hammen, C., Hazel, N. A., Brennan, P. A., \& Najman, J. (2012). Intergenerational transmission and continuity of stress and depression: Depressed women and their offspring in 20 years of follow-up. Psychological Medicine, 42, 931-942.

Hankin, B. L., \& Abramson, L. Y. (2001). Development of gender differences in depression: An elaborated cognitive vulnerability-transactional stress theory. Psychological Bulletin, 127, 773-796.

Hankin, B. L., Abramson, L. Y., Moffitt, T. E., Silva, P. A., McGee, R., \& Angell, K. E. (1998). Development of depression from preadolescence to young adulthood: Emerging gender differences in a 10-year longitudinal study. Journal of Abnormal Psychology, 107, 128.

Hankin, B. L., Mermelstein, R., \& Roesch, L. (2007). Sex differences in adolescent depression: Stress exposure and reactivity models. Child Development, 78, 279-295.

Hankin, B. L., Oppenheimer, C., Jenness, J., Barrocas, A., Shapero, B. G., \& Goldband, J. (2009). Developmental origins of cognitive vulnerabilities to depression: Review of processes contributing to stability and change across time. Journal of Clinical Psychology, 65, 1327-1338.

Hankin, B. L., Stone, L. B., \& Wright, P. A. (2010). Corumination, interpersonal stress generation, and internalizing symptoms: Accumulating effects and transactional influences in a multiwave study of adolescents. Development and Psychopathology, 22, 217-235.

Harrison, A. J., \& Gibb, B. E. (2014). Attentional biases in currently depressed children: An eye-tracking study of biases in sustained attention to emotional stimuli. Journal of Clinical Child \& Adolescent Psychology. Advance online publication.

Hart, C. H., Nelson, D. A., Robinson, C. C., Olsen, S. F., \& McNeilly-Choque, M. K. (1998). Overt and relational aggression in Russian nurseryschool-age children: Parenting style and marital linkages. Developmental Psychology, 34, 687.

Harter, S. (1993). Causes and consequences of low self-esteem in children and adolescents. In Self-esteem (pp. 87-116). New York: Springer.

Harvey, A., Watkins, E., Mansell, W., \& Shafran, R. (2004). Cognitive behavioural processes across disorders: A transdiagnostic approach to research and treatment. New York: Oxford University Press.

Harvey, M., \& Byrd, M. (2000). Relationships between adolescents' attachment styles and family functioning. Adolescence, 35, 345-356.

Henderlong, J., \& Lepper, M. R. (2002). The effects of praise on children's intrinsic motivation: A review and synthesis. Psychological Bulletin, 128, 774.

Hertel, P. T., \& Mathews, A. (2011). Cognitive bias modification past perspectives, current findings, and future applications. Perspectives on Psychological Science, 6, 521-536.

Hettema, J. M. (2008). What is the genetic relationship between anxiety and depression? American Journal of Medical Genetics, 148, 140-146.

Hodges, W. F., Tierney, C. W., \& Buchsbaum, H. K. (1984). The cumulative effect of stress on preschool children of divorced and intact families. Journal of Marriage and the Family, 46, 611-617.

Hops, H. (1992). Parental depression and child behaviour problems: Implications for behavioural family intervention. Behaviour Change, 9, 126-138.

Irons, C., \& Gilbert, P. (2005). Evolved mechanisms in adolescent anxiety and depression symptoms: The role of the attachment and social rank systems. Journal of Adolescence, 28, 325-341.

Israel, A. C., \& Roderick, H. A. (2001). A measure of the stability of family activities: An initial examination. Assessment, 8, 417-424.

Israel, A. C., Roderick, H. A., \& Ivanova, M. Y. (2002). A measure of the stability of activities in a family environment. Journal of Psychopathology and Behavioral Assessment, 24, 85-95.

Ivanova, M. Y., Achenbach, T. M., Dumenci, L., Rescorla, L. A., Almqvist, F., Weintraub, S., et al. (2007). Testing the 8-syndrome structure of the child behavior checklist in 30 societies. Journal of Clinical Child and Adolescent Psychology, 36, 405-417.

Ivanova, M. Y., \& Israel, A. C. (2005). Family stability as a protective factor against the influences of pessimistic attributional style on depression. Cognitive Therapy and Research, 29, 243-251. 
Jacobvitz, D., Hazen, N., Curran, M., \& Hitchens, K. (2004). Observations of early triadic family interactions: Boundary disturbances in the family predict symptoms of depression, anxiety, and attention-deficit/hyperactivity disorder in middle childhood. Developmental Psychopathology, 16, $577-592$.

Jenkins, J. M., \& Smith, M. A. (1990). Factors protecting children living in disharmonious homes: Maternal reports. Journal of the American Academy of Child \& Adolescent Psychiatry, 29, 60-69.

Johnson, J. H. (1982). Life events as stressors in childhood and adolescence. In B. B. Lahey \& A. E. Kazdin (Eds.), Advances in clinical child psychology (Vol. 5, pp. 219-253). New York: Plenum Press.

Joormann, J., Talbot, L., \& Gotlib, I. H. (2007). Biased processing of emotional information in girls at risk for depression. Journal of Abnormal Psychology, 116, 135-143.

Jouriles, E. N., Spiller, L. C., Stephens, N., McDonald, R., \& Swank, P. (2000). Variability in adjustment of children of battered women: The role of child appraisals of interparent conflict. Cognitive Therapy and Research, 24, 233-249.

Kashani, J. H., Cantwell, D. P., Shekim, W. O., \& Reid, J. C. (1982). Major depressive disorder in children admitted to an inpatient community mental health center. American Journal of Psychiatry, 139, 671-672.

Kaslow, N. J., Broth, M. R., Smith, C. O., \& Collins, M. H. (2012). Familybased interventions for child and adolescent disorders. Journal of Marital and Family Therapy, 38, 82-100.

Kaslow, N. J., Deering, C. G., \& Racusin, G. R. (1994). Depressed children and their families. Clinical Psychology Review, 14, 39-59.

Keeton, C. P., Teetsel, R. N., Dull, N. M. S., \& Ginsburg, G. S. (in press). Parent psychopathology and children's psychological health: Moderation by sibling relationship dimensions. Journal of Abnormal Child Psychology.

Kelly, J. B. (2000). Children's adjustment in conflicted marriage and divorce: A decade review of research. Journal of the American Academy of Child \& Adolescent Psychiatry, 39, 963-973.

Kendall, P., \& Hedtke, K. (2006). Coping cat workbook (3rd ed.). Ardmore, PA: Workbook Publishing.

Kendall, P. C., Furr, J. M., \& Podell, J. L. (2010). Child-focused treatment of anxiety. In J. R. Weisz \& A. E. Kazdin (Eds.), Evidence-based psychotherapies for children and adolescents (2nd ed., pp. 45-60). New York: Guilford Press.

Kendall, P. C., Hudson, J. L., Gosch, E., Flannery-Schroeder, E., \& Suveg, C. (2008). Cognitive-behavioral therapy for anxiety disordered youth: A randomized clinical trial evaluating child and family modalities. Journal of Consulting and Clinical Psychology, 76, 282.

Kerig, P. K., Cowan, P. A., \& Cowan, C. P. (1993). Marital quality and gender differences in parent-child interaction. Developmental Psychology, 29, 931.

Kessler, R. C., Avenevoli, S., Costello, E. J., Georgiades, K., Green, J. G., Gruber, M. J., et al. (2012). Prevalence, persistence, and sociodemographic correlates of DSM-IV disorders in the National Comorbidity Survey Replication Adolescent Supplement. Archives of General Psychiatry, 69, 372-380.

Kim, H. K., Capaldi, D. M., Pears, K. C., Kerr, D. C. R., \& Owen, L. D. (2009). Intergenerational transmission of internalizing and externalizing behaviors across three generations: Gender-specific pathways. Criminal Behavior and Mental Health, 19, 125-141.

Kivisto, K. L., Welsh, D. P., Darling, N., \& Culpepper, C. L. (2015). Family enmeshment, adolescent emotional dysregulation, and the moderating role of gender. Journal of Family Psychology, 29, 604.

Kovacs, M., \& Devlin, B. (1998). Internalizing disorders in childhood. Journal of Child Psychology and Psychiatry, and Allied Disciplines, 39, 47-63.

Kowal, A., \& Kramer, L. (1997). Children's understanding of parental differential treatment. Child Development, 68, 113-126.

Kowal, A., Kramer, L., Krull, J. L., \& Crick, N. R. (2002). Children's perceptions of the fairness of parental preferential treatment and their socioemotional well-being. Journal of Family Psychology, 16, 297-306.

Kramer, L. (2004). Experimental intervention in sibling relationships. In R. D. Conger, F. O. Lorenz, \& K. A. S. Wickrama (Eds.), Continuity and change in family relations. Mahwah, NJ: Erlbaum.

Krueger, R. F., Chentsova-Dutton, Y. E., Markon, K. E., Goldberg, D., \& Ormel, J. (2003). A cross-cultural study of the structure of comorbidity among common psychopathological syndromes in the general health care setting. Journal of Abnormal Psychology, 112, 437.

Krueger, R. F., \& Markon, K. E. (2011). A dimensional-spectrum model of psychopathology: Progress and opportunities. Archives of General Psychiatry, 68, 10-11.
Krueger, R. F., \& Markon, K. E. (2014). The role of the DSM-5 personality trait model in moving toward a quantitative and empirically based approach to classifying personality and psychopathology. Annual Review of Clinical Psychology, 10, 477-501.

Kujawa, A. J., Torpey, D., Kim, J., Hajcak, G., Rose, S., Gotlib, I. H., et al. (2011). Attentional biases for emotional faces in young children of mothers with chronic or recurrent depression. Journal of Abnormal Child Psychology, 39, 125-135.

Larson, R., \& Richards, M. H. (1994). Divergent realities: The emotional lives of mothers, fathers, and adolescents. New York: Basic Books.

Lau, J. Y., Rijsdijk, F., \& Eley, T. C. (2006). I think, therefore I am: A twin study of attributional style in adolescents. Journal of Child Psychology and Psychiatry, 47, 696-703.

Laurent, H. K., Kim, H. K., \& Capaldi, D. M. (2008). Prospective effects of interparental conflict on child attachment security and the moderating role of parents' romantic attachment. Journal of Family Psychology, 22, 377.

Leach, L. S., Christensen, H., Mackinnon, A. J., Windsor, T. D., \& Butterworth, P. (2008). Gender differences in depression and anxiety across the adult lifespan. Social Psychiatry and Psychiatric Epidemiology, 43, 983-998.

Lee, A., \& Hankin, B. L. (2009). Insecure attachment, dysfunctional attitudes, and low self-esteem predicting prospective symptoms of depression and anxiety during adolescence. Journal of Clinical Child and Adolescent Psychology, 38, 219-231.

Leung, K., Lau, S., \& Lam, W. (1998). Parenting styles and academic achievement: A cross-cultural study. Merrill-Palmer Quarterly, 44, 157-167.

Lewinsohn, P. M., Gotlib, I. H., Lewinsohn, M., Seeley, J. R., \& Allen, N. B. (1998). Gender differences in anxiety disorders and anxiety symptoms in adolescents. Journal of Abnormal Psychology, 107, 109.

Lewinsohn, P. M., Hops, H., Roberts, R. E., Seeley, J. R., \& Andrews, J. A. (1993). Adolescent psychopathology: I. Prevalence and incidence of depression and other DSM-III-R disorders in high school students. Journal of Abnormal Psychology, 102, 133.

Lewis, G., Rice, F., Harold, G. T., Collishaw, S., \& Thapar, A. (2011). Investigating environmental links between parent depression and child depressive/anxiety symptoms using an assisted conception design. Journal of the American Academy of Child \& Adolescent Psychiatry, 50, 451-459.

Litovsky, V. G., \& Dusek, J. B. (1985). Perceptions of child rearing and selfconcept development during the early adolescent years. Journal of Youth and Adolescence, 14, 373-387.

Long, N., Slater, E., Forehand, R., \& Fauber, R. (1988). Continued high or reduced interparental conflict following divorce: Relation to young adolescent adjustment. Journal of Consulting and Clinical Psychology, 56, 467-469.

Lowther, H., \& Newman, E. (2014). Attention bias modification (ABM) as a treatment for child and adolescent anxiety: A systematic review. Journal of Affective Disorders, 168, 125-135.

Luby, J., Lenze, S., \& Tillman, R. (2012). A novel early intervention for preschool depression: Findings from a pilot randomized controlled trial. Journal of Child Psychology and Psychiatry, 53, 313-322.

Maccoby, E. E. (1990). Gender and relationships: A developmental account. American Psychologist, 45, 513.

Markson, S., \& Fiese, B. H. (2000). Family rituals as a protective factor for children with asthma. Journal of Pediatric Psychology, 25, 471-479.

Martins, C., \& Gaffan, E. (2000). Effects of early maternal depression on patterns of infant mother attachment: A meta-analytic investigation. Journal of Child Psychology and Psychiatry, 41, 737-746.

McCubbin, H. I., \& Patterson, J. M. (1983). The family stress process: The double ABCX model of adjustment and adaptation. Marriage \& Family Review, 6, 7-37.

McGinn, L. K., Cukor, D., \& Sanderson, W. C. (2005). The relationship between parenting style, cognitive style, and anxiety and depression: Does increased early adversity influence symptom severity through the mediating role of cognitive style? Cognitive Therapy and Research, 29, 219-242.

McLaughlin, K. A., \& Nolen-Hoeksema, S. (2011). Rumination as a transdiagnostic factor in depression and anxiety. Behaviour Research and Therapy, 49, 186-193.

McLeod, B. D., Weisz, J. R., \& Wood, J. J. (2007). Examining the association between parenting and childhood depression: A meta-analysis. Clinical Psychology Review, 27, 986-1003.

McLeod, B. D., Wood, J. J., \& Weisz, J. R. (2007). Examining the association between parenting and childhood anxiety: A meta-analysis. Clinical Psychology Review, 27, 155-172. 
Mezulis, A. H., Hyde, J. S., \& Abramson, L. Y. (2006). The developmental origins of cognitive vulnerability to depression: Temperament, parenting, and negative life events in childhood as contributors to negative cognitive style. Developmental Psychology, 42, 1012-1025.

Mikulincer, M., \& Florian, V. (1999). Maternal-fetal bonding, coping strategies, and mental health during pregnancy-The contribution of attachment style. Journal of Social and Clinical Psychology, 18, 255-276.

Milevsky, A., \& Levitt, M. J. (2005). Sibling support in early adolescence: Buffering and compensation across relationships. European Journal of Developmental Psychology, 2, 299-320.

Minuchin, S. (1974). Families and family therapy. Cambridge, MA: Harvard University Press.

Miu, A. S., \& Yeager, D. S. (in press). Preventing symptoms of depression by teaching adolescents that people can change: Effects of a brief incremental theory of personality intervention at 9-month follow-up. Clinical Psychological Science.

Moffitt, T. E., Harrington, H., Caspi, A., Kim-Cohen, J., Goldberg, D., Gregory, A. M., et al. (2007). Depression and generalized anxiety disorder: Cumulative and sequential comorbidity in a birth cohort followed prospectively to age 32 years. Archives of General Psychiatry, 64, 651-660.

Mogg, K., Wilson, K. A., Hayward, C., Cunning, D., \& Bradley, B. P. (2012). Attentional biases for threat in at-risk daughters and mothers with lifetime panic disorder. Journal of Abnormal Psychology, 121, 852-862.

Moreira, J. F. G., \& Telzer, E. H. (2015). Changes in family cohesion and links to depression during the college transition. Journal of Adolescence, $43,72-82$.

Morris, A. S., Silk, J. S., Steinberg, L., Myers, S. S., \& Robinson, L. R. (2007). The role of the family context in the development of emotion regulation. Social Development, 16, 361-388.

Mueller, C. M., \& Dweck, C. S. (1998). Praise for intelligence can undermine children's motivation and performance. Journal of Personality and Social Psychology, 75, 33.

Muris, P., Bögels, S., Meesters, C., van der Kamp, N., \& van Oosten, A. (1996). Parental rearing practices, fearfulness, and problem behaviour in clinically referred children. Personality and Individual Differences, $21,813-818$.

Muris, P., \& Meesters, C. (2002). Attachment, behavioral inhibition, and anxiety disorders symptoms in normal adolescents. Journal of Psychopathology and Behavioral Assessment, 24, 97-106.

Muris, P., Meesters, C., Van Melick, M., \& Zwambag, L. (2001). Self-reported attachment style, attachment quality, and symptoms of anxiety and depression in young adolescents. Personality and Individual Differences, 30, 809-818.

Muris, P., \& Merckelbach, H. (1998). Perceived parental rearing behaviour and anxiety disorders symptoms in normal children. Personality and Individual Differences, 25, 1199-1206.

Murray, L., \& Cooper, P. J. (1997). Effects of postnatal depression on infant development. Archives of Disease in Childhood, 77, 99-101.

Nanda, M. M., Kotchick, B. A., \& Grover, R. L. (2012). Parental psychological control and childhood anxiety: The mediating role of perceived lack of control. Journal of Child and Family Studies, 21, 637-645.

National Institute of Mental Health. (2015). NIMH Strategic Plan for Research (NIH Publication No. 02-2650). Retrieved from http://www. nimh.nih.gov/about/strategic-planning-reports/index.shtml

Nolen-Hoeksema, S., \& Girgus, J. S. (1994). The emergence of gender differences in depression during adolescence. Psychological Bulletin, 115, 424.

Nomura, Y., Wickramaratne, P. J., Warner, V., Mufson, L., \& Weissman, M. M. (2002). Family discord, parental depression, and psychopathology in offspring: Ten-year follow-up. Journal of the American Academy of Child \& Adolescent Psychiatry, 41, 402-409.

Noordhof, A., Krueger, R. F., Ormel, J., Oldehinkel, A. J., \& Hartman, C. A. (2014). Integrating autism-related symptoms into the dimensional internalizing and externalizing model of psychopathology. The TRAILS study. Journal of Abnormal Child Psychology, 43, 577-587.

Nowicki, S., \& Strickland, B. R. (1973). A locus of control scale for children. Journal of Consulting and Clinical Psychology, 40, 148.

Ollendick, T. H., Jarrett, M. A., Grills-Taquechel, A. E., Hovey, L. D., \& Wolff, J. C. (2008). Comorbidity as a predictor and moderator of treatment outcome in youth with anxiety, affective, attention deficit/hyperactivity disorder, and oppositional/conduct disorders. Clinical Psychology Review, 28, 1447-1471.

Olson, D. H., Russell, C. S., \& Sprenkle, D. H. (1983). Circumplex model of marital and family systems: Vl. Theoretical update. Family Process, 22, 69-83.
Olson, S. L., Ceballo, R., \& Park, C. (2002). Early problem behavior among children from low income, mother headed families: A multiple risk perspective. Journal of Clinical Child and Adolescent Psychology, 31 , 419-430.

Owen, M. T., \& Cox, M. J. (1997). Marital conflict and the development of infant-parent attachment relationships. Journal of Family Psychology, $11,152$.

Padilla-Walker, L. M., Harper, J. M., \& Jensen, A. C. (2010). Self-regulation as a mediator between sibling relationship quality and early adolescents' positive and negative outcomes. Journal of Family Psychology, 24, 419.

Paikoff, R. L., \& Brooks-Gunn, J. (1991). Do parent-child relationships change during puberty? Psychological Bulletin, 110, 47-66.

Panzarella, C., Alloy, L. B., \& Whitehouse, W. G. (2006). Expanded hopelessness theory of depression: On the mechanisms by which social support protects against depression. Cognitive Therapy and Research, 30, 307-333.

Parke, R. D., \& Buriel, R. (2006). Socialization in the family: Ethnic and ecological perspectives. In W. Damon \& R. M. Lerner (Series Eds.) \& N. Eisenberg (Vol. Ed.), Handbook of child psychology (6th ed., pp. 429-504). Hoboken, NJ: Wiley.

Pearson, R. M., Evans, J., Kounali, D., Lewis, G., Heron, J., Ramchandani, P. G., et al. (2013). Maternal depression during pregnancy and the postnatal period: Risks and possible mechanisms for offspring depression at age 18 years. JAMA Psychiatry, 70, 1312-1319.

Peleg-Popko, O., \& Dar, R. (2001). Marital quality, family patterns, and children's fears and social anxiety. Contemporary Family Therapy, 23, 465487.

Peterson, C., \& Steen, T. A. (2002). Optimistic explanatory style. Handbook of positive psychology (pp. 244-256). New York: Oxford University Press.

Pettit, G. S., Laird, R. D., Dodge, K. A., Bates, J. E., \& Criss, M. M. (2001). Antecedents and behavior-problem outcomes of parental monitoring and psychological control in early adolescence. Child Development, 72, 583-598.

Phillips, M. L., Drevets, W. C., Rauch, S. L., \& Lane, R. (2003). Neurobiology of emotion perception: I. The neural basis of normal emotion perception. Biological Psychiatry, 54, 504-514.

Pincus, D. B, Chase, R., Chow, C. W, Weiner, C. L, Cooper-Vince, C., \& Eyberg, S. M. (2010). Efficacy of modified parent-child interaction therapy for young children with separation anxiety disorder. Paper presented at the 44th annual meeting of the Association of Behavioral and Cognitive Therapies, San Francisco, CA.

Pitica, I., Susa, G., \& Benga, O. (2010). The effects of attentional training on attentional allocation to positive and negative stimuli in school-aged children: An explorative single case investigation. Cognition, Brain, Behavior, 14, 63-78.

Pomerantz, E. M., \& Kempner, S. G. (2013). Mothers' daily person and process praise: Implications for children's theory of intelligence and motivation. Developmental Psychology, 49, 2040-2046.

Pomerantz, E. M., \& Ruble, D. N. (1998). The role of maternal control in the development of sex differences in child self-evaluative factors. Child $D e-$ velopment, 69, 458-478.

Puliafico, A. C., Comer, J. S., \& Albano, A. M. (2013). Coaching approach behavior and leading by modeling: Rationale, principles, and a sessionby-session description of the CALM Program for early childhood anxiety. Cognitive and Behavioral Practice, 20, 517-528.

Rapee, R. M. (2001). The development of generalized anxiety. In M. W. Vasey \& M. R. Dadds (Eds.), The developmental psychopathology of anxiety (pp. 481-503). Oxford: Oxford University Press.

Rapee, R. M. (2012). Family factors in the development and management of anxiety disorders. Clinical Child and Family Psychology Review, 15, 6980.

Ravindran, N., Engle, J. M., Mcelwain, N. L., \& Kramer, L. (2015). Fostering parents' emotion regulation through a sibling-focused experimental intervention. Journal of Family Psychology, 29, 458-468.

Reid, S. C., Salmon, K., \& Lovibond, P. F. (2006). Cognitive biases in childhood anxiety, depression, and aggression: Are they pervasive or specific? Cognitive Therapy and Research, 30, 531-549.

Repetti, R. L. (1987). Individual and common components of the social environment at work and psychological well-being. Journal of Personality and Social Psychology, 52, 710.

Rhoades, K. A. (2008). Children's responses to interparental conflict: A meta-analysis of their associations with child adjustment. Child Development, 79, 1942-1956. 
Riemann, B. C., Kuckertz, J. M., Rozenman, M., Weersing, V. R., \& Amir, N. (2013). Augmentation of youth cognitive behavioral and pharmacological interventions with attention modification: A preliminary investigation. Depression and Anxiety, 30, 822-828.

Rogers, C. R. (1960). A therapist's view of personal goals (Pendle Hill Pamphlet No. 108). Wallingford: PA: Pendle Hill.

Rohner, R. P. (1975). They love me, they love me not: A worldwide study of the effects of parental acceptance rejection. New Haven, CT: HRAF.

Romero, C., Master, A., Paunesku, D., Dweck, C. S., \& Gross, J. J. (2014). Academic and emotional functioning in middle school: The role of implicit theories. Emotion, 14, 227-234.

Roy, A. K., Vasa, R. A., Bruck, M., Mogg, K., Bradley, B. P., Sweeney, M., et al. (2008). Attention bias toward threat in pediatric anxiety disorders. Journal of the American Academy of Child \& Adolescent Psychiatry, 47, 1189-1196.

Ruble, D. N., Greulich, F., Pomerantz, E. M., \& Gochberg, B. (1993). The role of gender-related processes in the development of sex differences in self-evaluation and depression. Journal of Affective Disorders, 29, 97-128.

Rudolph, K. D. (2002). Gender differences in emotional responses to interpersonal stress during adolescence. Journal of Adolescent Health, 30, 3-13.

Rudolph, K. D. (2010). Implicit theories of peer relationships. Social Development, 19, 113-129.

Rudolph, K. D., \& Hammen, C. (1999). Age and gender as determinants of stress exposure, generation, and reactions in youngsters: A transactional perspective. Child Development, 70, 660-677.

Rutter, M., Lebovici, S., Eisenberg, L., Sneznevskij, A. V., Sadoun, R., Brooke, E., et al. (1969). A triaxial classification of mental disorders in childhood. Journal of Child Psychology and Psychiatry, 10, 41-61.

Sameroff, A. J. (2000). Developmental systems and psychopathology. Development and Psychopathology, 12, 297-312.

Sander, J. B., \& McCarty, C. A. (2005). Youth depression in the family context: Familial risk factors and models of treatment. Clinical Child and Family Psychology Review, 8, 203-219.

Schleider, J. L., Abel, M. R., \& Weisz, J. R. (2015). Implicit theories and youth mental health problems: A random-effects meta-analysis. Clinical Psychology Review, 35, 1-9.

Schleider, J. L., Chorpita, B. F., \& Weisz, J. R. (2014). Relation between parent psychiatric symptoms and youth problems: Moderation through family structure and youth gender. Journal of Abnormal Child Psychology, $42,195-204$.

Schleider, J. L., Ginsburg, G. S., Keeton, C. P., Weisz, J. R, Birmaher, B., Kendall, P. C., et al. (2015). Parent symptoms and treatment outcomes for anxious youth: Roles of family functioning and caregiver strain. Journal of Consulting and Clinical Psychology, 83, 213-224.

Schleider, J. L., Krause, E. D., \& Gillham, J. E. (2014). Sequential comorbidity of anxiety and depression in youth: Present knowledge and future directions. Current Psychiatry Reviews, 10, 75-87.

Schleider, J. L., Patel, A., Krumholz, L., Chorpita, B. F., \& Weisz, J. R. (2015). Relations between parent symptomatology and youth problems: Multiple mediation through family income and parent-youth stress. Child Psychiatry \& Human Development, 46, 1-9.

Schleider, J. L., Vélez, C. E., Krause, E. D., \& Gillham, J. (2014). Perceived psychological control and anxiety in early adolescents: The mediating role of attributional style. Cognitive Therapy and Research, 38, 71-81.

Schleider, J. L., \& Weisz, J. R. (2015). Using Mechanical Turk to study family processes and youth mental health: A test of feasibility. Journal of Child and Family Studies, 24, 3235-3246.

Schleider, J. L., \& Weisz, J. R. (2016). Mental health problems and implicit theories of thoughts, feelings, and behavior in early adolescents: Are girls at greater risk? Journal of Social and Clinical Psychology, 35, 135-149.

Schleider, J. L., \& Weisz, J. R. (in press). Implicit theories relate to youth psychopathology, but how? A longitudinal test of two predictive models. Child Psychiatry and Human Development.

Sears, R. R., Macoby, E., \& Levin, H. (1957). Patterns of child rearing. Evanston, IL: Row, Peterson.

Shanahan, L., McHale, S. M., Crouter, A. C., \& Osgood, D. W. (2008). Linkages between parents' differential treatment, youth depressive symptoms, and sibling relationships. Journal of Marriage and Family, 70, 480-494.

Shechner, T., Rimon-Chakir, A., Britton, J. C., Lotan, D., Apter, A., Bliese, P. D., et al. (2014). Attention bias modification treatment augmenting effects on cognitive behavioral therapy in children with anxiety: Random- ized controlled trial. Journal of the American Academy of Child \& Adolescent Psychiatry, 53, 61-71.

Shih, J. H., Eberhart, N. K., Hammen, C. L., \& Brennan, P. A. (2006). Differential exposure and reactivity to interpersonal stress predict sex differences in adolescent depression. Journal of Clinical Child and Adolescent Psychology, 35, 103-115.

Siegenthaler, E., Munder, T., \& Egger, M. (2012). Effect of preventive interventions in mentally ill parents on the mental health of the offspring: Systematic review and meta-analysis. Journal of the American Academy of Child \& Adolescent Psychiatry, 51, 8-17.

Siegle, D., Rubenstein, L. D. V., Pollard, E., \& Romey, E. (2010). Exploring the relationship of college freshmen honor students' effort and ability attribution, interest, and implicit theory of intelligence with perceived ability. Gifted Child Quarterly, 54, 92-101.

Siqueland, L., Rynn, M., \& Diamond, G. S. (2005). Cognitive behavioral and attachment based family therapy for anxious adolescents: Phase I and II studies. Journal of Anxiety Disorders, 19, 361-381.

Sokolowski, K. L., \& Israel, A. C. (2008). Perceived anxiety control as a mediator of the relationship between family stability and adjustment. Journal of Anxiety Disorders, 22, 1454-1461.

Spera, C. (2005). A review of the relationship among parenting practices, parenting styles, and adolescent school achievement. Educational Psychology Review, 17, 125-146.

Stange, J. P., Hamilton, J. L., Abramson, L. Y., \& Alloy, L. B. (2014). A vulnerability-stress examination of response styles theory in adolescence: Stressors, sex differences, and symptom specificity. Journal of Clinical Child \& Adolescent Psychology, 43, 813-827.

Stark, K. D., Humphrey, L. L., Crook, K., \& Lewis, K. (1990). Perceived family environments of depressed and anxious children: Child's and maternal figure's perspectives. Journal of Abnormal Child Psychology, 18 , $527-547$.

Steinberg, L., \& Monahan, K. C. (2007). Age differences in resistance to peer influence. Developmental Psychology, 43, 1531.

Stevenson-Hinde, J. (1990). Attachment within family systems: An overview. Infant Mental Health Journal, 11, 218-227.

Stocker, C. M., Burwell, R. A., \& Briggs, M. L. (2002). Sibling conflict in middle childhood predicts children's adjustment in early adolescence. Journal of Family Psychology, 16, 50.

Stocker, C., Dunn, J., \& Plomin, R. (1989). Sibling relationships: Links with child temperament, maternal behaviour, and family structure. Child Development, $60,715-727$.

Sturge-Apple, M. L., Davies, P. T., \& Cummings, E. M. (2006). Impact of hostility and withdrawal in interparental conflict on parental emotional unavailability and children's adjustment difficulties. Child Development, 77, 1623-1641.

Sylvester, C. M., Hudziak, J. J., Gaffrey, M. S., Barch, D. M., \& Luby, J. L. (in press). Stimulus-driven attention, threat bias, and sad bias in youth with a history of an anxiety disorder or depression. Journal of Abnormal Child Psychology.

Symonds, P. M. (1939). The psychology of parent-child relationships. New York: Appleton-Century-Crofts.

Taylor, L., \& Ingram, R. E. (1999). Cognitive reactivity and depressotypic information processing in children of depressed mothers. Journal of $A b-$ normal Psychology, 108, 202-210.

Teachman, B. A., Joormann, J., Steinman, S. A., \& Gotlib, I. H. (2012). Automaticity in anxiety disorders and major depressive disorder. Clinical Psychology Review, 32, 575-603.

Telzer, E. H., \& Fuligni, A. J. (2013). Positive daily family interactions eliminate gender differences in internalizing symptoms among adolescents Journal of Youth and Adolescence, 42, 1498-1511.

Teubert, D., \& Pinquart, M. (2010). The association between coparenting and child adjustment: A meta-analysis. Parenting: Science and Practice, 10 , 286-307.

Thomaes, S., Brummelman, E., Bushman, B. J., Reijntjes, A., \& Orobio de Castro, B. (2013). Is it time to rethink the pervasiveness and nature of low self-esteem in children? Unpublished manuscript.

Thompson, M., Kaslow, N. J., Weiss, B., \& Nolen-Hoeksema, S. (1998) Children's Attributional Style Questionnaire-Revised: Psychometric examination. Psychological Assessment, 10, 166.

Thompson, R. A. (1994). Emotion regulation: A theme in search of definition. Monographs of the Society for Research in Child Development, $59,25-52$.

Trosper, S. E., Buzzella, B. A., Bennett, S. M., \& Ehrenreich, J. T. (2009). Emotion regulation in youth with emotional disorders: Implications for 
a unified treatment approach. Clinical Child and Family Psychology Review, 12, 234-254.

Tucker, C. J., Finkelhor, D., Turner, H., \& Shattuck, A. (2013). Association of sibling aggression with child and adolescent mental health. Pediatrics, $132,79-84$

Turner, J. E., \& Cole, D. A. (1994). Developmental differences in cognitive diatheses for child depression. Journal of Abnormal Child Psychology, $22,15-32$.

van Brakel, A. M., Muris, P., Bögels, S. M., \& Thomassen, C. (2006). A multifactorial model for the etiology of anxiety in non-clinical adolescents: Main and interactive effects of behavioral inhibition, attachment and parental rearing. Journal of Child and Family Studies, 15, 568-578.

van IJzendoorn, M. H., Schuengel, C., \& Bakermans-Kranenburg, M. J. (1999). Disorganized attachment in early childhood: Meta-analysis of precursors, concomitants, and sequelae. Development and Psychopathology, 11, 225-250.

Volling, B. L., McElwain, N. L., \& Miller, A. L. (2002). Emotion regulation in context: The jealousy complex between young siblings and its relations with child and family characteristics. Child Development, 73, 581-600.

Wadsworth, M. E., Hudziak, J. J., Heath, A. C., \& Achenbach, T. M. (2001). Latent class analysis of child behavior checklist anxiety/depression in children and adolescents. Journal of the American Academy of Child \& Adolescent Psychiatry, 40, 106-114.

Waters, A. M., Mogg, K., Bradley, B. P., \& Pine, D. S. (2008). Attentional bias for emotional faces in children with generalized anxiety disorder. Journal of the American Academy of Child \& Adolescent Psychiatry, 47, 435-442.

Weems, C. F., \& Stickle, T. R. (2005). Anxiety disorders in childhood: Casting a nomological net. Clinical Child and Family Psychology Review, 8, $107-134$.

Weersing, V. R., Rozenman, M. S., Maher-Bridge, M., \& Campo, J. V. (2012). Anxiety, depression, and somatic distress: Developing a transdiagnostic internalizing toolbox for pediatric practice. Cognitive and Behavioral Practice, 19, 68-82.

Weissman, M. M., Warner, V., Wickramaratne, P., Moreau, D., \& Olfson, M. (1997). Offspring of depressed parents: 10 years later. Archives of General Psychiatry, 54, 932-940.

Weissman, M. M., Wickramaratne, P., Nomura, Y., Warner, V., Pilowsky, D., \& Verdeli, H. (2006). Offspring of depressed parents: 20 years later. American Journal of Psychiatry, 163, 1001-1008.

Weisz, J. R., Bearman, S. K., Santucci, L. S., \& Jensen-Doss, A. (2016). Initial test of a principle-guided approach to transdiagnostic youth psychotherapy. Manuscript submitted for publication.

Weisz, J. R., Chorpita, B .F., Palinkas, L. A., Schoenwald, S. K., Miranda, J., Bearman, S. K., et al. (2012). Testing standard and modular designs for psychotherapy with youth depression, anxiety, and conduct problems: A randomized effectiveness trial. Archives of General Psychiatry, 69, 274-282.

Weisz, J. R., McCarty, C. A., \& Valeri, S. M. (2006). Effects of psychotherapy for depression in children and adolescents: A meta-analysis. Psychological Bulletin, 132, 132-149.

Weisz, J. R., Moore, P. S., Southam-Gerow, M. A., Weersing, V. R., Valeri, S. M., \& McCarty, C. A. (2005). Therapist's manual PASCET: Primary and Secondary Control Enhancement Training Program (3rd ed.). Los Angeles: University of California Press.

Weisz, J. R., Southam-Gerow, M. A., \& McCarty, C. A. (2001). Control-related beliefs and depressive symptoms in clinic-referred children and adolescents: Developmental differences and model specificity. Journal of Abnormal Psychology, 110, 97.

Wenar, C., \& Kerig, P. (2000). Developmental psychopathology: From infancy through adolescence. New York: McGraw-Hill.

Wickramaratne, P. J., \& Weissman, M. M. (1998). Onset of psychopathology in offspring by developmental phase and parental depression. Journal of the American Academy of Child \& Adolescent Psychiatry, 37, 933-942.

Wight, R. G., Aneshensel, C. S., Botticello, A. L., \& Sepúlveda, J. E. (2005) A multilevel analysis of ethnic variation in depressive symptoms among adolescents in the United States. Social Science \& Medicine, 60, 2073 2084.

Wilson, M. E., White, M. A., Cobb, B., Curry, R., Greene, D., \& Popovich, D. (2000). Family dynamics, parental fetal attachment and infant temperament. Journal of Advanced Nursing, 31, 204-210.

Wood, J. J., Piacentini, J. C., Southam-Gerow, M., Chu, B. C., \& Sigman, M. (2006). Family cognitive behavioral therapy for child anxiety disorders. Journal of the American Academy of Child \& Adolescent Psychiatry, 45, 314-321.

Yap, M. B., Allen, N. B., \& Ladouceur, C. D. (2008). Maternal socialization of positive affect: The impact of invalidation on adolescent emotion regulation and depressive symptomatology. Child Development, 79, 14151431.

Yeager, D. S., Johnson, R., Spitzer, B. J., Trzesniewski, K. H., Powers, J., \& Dweck, C. S. (2014). The far reaching effects of believing people can change: Implicit theories of personality shape stress, health, and achievement during adolescence. Journal of Personality and Social Psychology, $106,867$.

Yoon, Y., Newkirk, K., \& Perry-Jenkins, M. (2015). Parenting stress, dinnertime rituals, and child well-being in working-class families. Family Relations, 64, 93-107.

Young, A. S., \& Fristad, M. A. (2015). Family-based interventions for childhood mood disorders. Child and Adolescent Psychiatric Clinics of North America. Advance online publication.

Yu, J. J., \& Gamble, W. C. (2008). Pathways of influence: Marital relationships and their association with parenting styles and sibling relationship quality. Journal of Child and Family Studies, 17, 757-778.

Zahn-Waxler, C., Cummings, E. M., McKnew, D. H., \& Radke-Yarrow, M. (1984). Altruism, aggression, and social interactions in young children with a manic-depressive parent. Child Development, 55, 112-122.

Zalta, A. K., \& Chambless, D. L. (2011). Testing a developmental model of anxiety with the Parental Facilitation of Mastery Scale. Journal of Anxiety Disorders, 25, 352-361.

Zalta, A. K., \& Chambless, D. L. (2012). Understanding gender differences in anxiety: The mediating effects of instrumentality and mastery. Psychology of Women Quarterly, 36, 488-499.

Zentall, S. R., \& Morris, B. J. (2010). "Good job, you're so smart": The effects of inconsistency of praise type on young children's motivation. Journal of Experimental Child Psychology, 107, 155-163. 